\title{
ENVIRONMENTAL MANAGEMENT IN THE FILM AND TELEVISION PRODUCTION INDUSTRY
}

\author{
By \\ Collingwood Brown \\ Bachelor of Engineering, McGill University, Quebec, Canada, 1997
}

A thesis presented to Ryerson University

In partial fulfillment of the requirements of

Master of Applied Science

In the program of

Environmental Applied Science and Management

Toronto, Ontario, Canada, 2013

(C) Collingwood Brown 2013 


\section{AUTHOR'S DECLARATION}

I hereby declare that I am the sole author of this thesis. This is a true copy of the thesis, including any required final revisions, as accepted by my examiners.

I authorize Ryerson University to lend this thesis to other institutions or individuals for the purpose of scholarly research.

I further authorize Ryerson University to reproduce this thesis by photocopying or by other means, in total or in part, at the request of other institutions or individuals for the purpose of scholarly research.

I understand that my thesis may be made electronically available to the public. 


\title{
ENVIRONMENTAL MANAGEMENT IN THE FILM AND TELEVISION PRODUCTION INDUSTRY
}

\author{
Master of Applied Science 2013 \\ Collingwood Brown \\ Environmental Applied Science and Management \\ Ryerson University
}

\begin{abstract}
The purpose of this research is to examine the current state of the film industry's environmental management efforts, by using the temporary structure of the film production itself as a framework. Film industry experts were interviewed, and a strengths, weaknesses, opportunities, and threats (SWOT) analysis was performed using the project-based organization (PBO) as a system boundary. The literature on environmental management for another project-based industry, construction, was reviewed and used as a comparison with the interview results. At present, the greatest strength of the PBO in pursuing environmental management is the social conscience of the employees within the PBO itself. The largest threat is the lack of financial resources. The construction comparison indicated that there was some divergence between the two industries, specifically with respect to competitive advantage and company image. The complex relationship each industry has with its stakeholders plays an important role in the ability to implement an environmental management program.
\end{abstract}

Keywords: Environmental management.

Project-based organizations.

Motion picture industry.

Film.

Construction.

SWOT Analysis. 


\section{TABLE OF CONTENTS}

AUTHOR'S DECLARATION ii

ABSTRACT iii

TABLE OF CONTENTS iv

LIST OF TABLES vi

LIST OF FIGURES vii

1.0 INTRODUCTION 1

$\begin{array}{ll}1.1 \text { Background } & 1\end{array}$

1.2 Purpose 2

2.0 LITERATURE REVIEW 4

2.1 Project-Based Organizations 4

2.1.1 Core Competencies, Knowledge Transfer, Innovation 5

2.1.2 Social Context

2.1.3 Research Gaps $\quad 10$

2.2 Construction as Project-Based Enterprise 11

2.2.1 Innovation 12

2.2.2 Green Innovation $\quad 13$

2.3 Film as Project-Based Enterprise 14

2.4 The Structure of the Film Industry 17

2.5 Environmental Management in Film Production 20

2.5.1 Environmental Impacts of Film Production $\quad 21$

2.5.2 Environmental Mitigation Strategies $\quad 25$

$\begin{array}{ll}\text { 2.5.3 Certification Options } & 27\end{array}$

2.5.3.1 Green Seal 28

2.5.3.2 BS 8909 EM Specification $\quad 30$

2.6 Sustainable Construction 32

2.6.1 Industry Drivers 32

2.6.2 Industry Barriers $\quad 36$

2.7 Summary 40

3.0 METHODOLOGY $\quad 41$

3.1 Key Informant Interviews $\quad 41$

3.2 SWOT Analysis $\quad 45$

\begin{tabular}{ll}
4.0 & RESULTS \\
\hline
\end{tabular}

4.1 Strengths $\quad 51$

4.2 Opportunities $\quad 58$

4.3 Weaknesses 63

$\begin{array}{ll}\text { 4.4 Threats } & 69\end{array}$

$\begin{array}{ll}\text { 5.0 DISCUSSION } & 76\end{array}$

$\begin{array}{ll}5.1 \text { Strengths and Opportunities } & 76\end{array}$

5.1.1 Strength: Social Conscience

5.1.2 Opportunity: Corporate Image 78 
$\begin{array}{ll}\text { 5.1.3 Opportunities Not Identified } & 79\end{array}$

5.2 Weaknesses and Threats 80

5.2.1 Weakness: Crew Cooperation 80

5.2.2 Threat: Budget $\quad 81$

5.2.3 Threat: Competitive Advantage $\quad 81$

5.2.4 Threat: Service and Product Availability $\quad 82$

5.3 Stakeholder Interests 83

5.4 Project-Based Organizations 84

$\begin{array}{ll}5.4 .1 \text { Innovation } & 85\end{array}$

5.4.2 Knowledge Transfer 86

5.4.3 Comparing Strengths and Opportunities with the Permanent Organization $\quad 89$

$\begin{array}{ll}\text { 5.4.4 Comparison Industry Review } & 91\end{array}$

5.5 Certification $\quad 92$

$\begin{array}{ll}\text { 6.0 CONCLUSIONS } & 94\end{array}$

6.1 Environmental Management SWOT Analysis for Film PBOs 94

6.2 Weaknesses and Threats and the PBO 96

6.3 Environmental Management SWOT Analysis for Construction PBOs 97

6.4 Contribution $\quad 99$

6.5 Future Research Opportunities 100

Appendix A: Interview Template 102

Appendix B: SWOT Analysis - Construction Industry 103

$\begin{array}{ll}\text { REFERENCES } & 109\end{array}$ 


\section{LIST OF TABLES}

1. Film industry sectors 18

2. Stages of film production 19

3. Environmental Media Association "Green Seal” 29 scorecard in 2007

4. Environmental Media Association "Green Seal" 30 scorecard in 2012

5. Construction industry barriers to environmental management 38

6. Occupational profiles of interview respondents 44

7. SWOT analysis of drivers and barriers 47

8. Results of SWOT analysis 50

9. Film and construction industry comparison review 91

10. Construction industry barrier SWOT analysis, based 104 on a review of the literature

11. Construction industry barrier SWOT analysis, based 106 on a review of the literature 


\section{LIST OF FIGURES}

1. Life Cycle Phases of a Film Production 24

2. Project-based organization as SWOT system boundary 46 


\subsection{INTRODUCTION}

\subsection{Background}

Even a cursory walk through a film production's construction shop will reveal what some insiders have known for years: there is a lot of needless waste. Scrap virgin wood fills 40-yard disposal bins. Plywood is hammered into scenic flats for sets, then torn down and tossed after the scene is shot; then the process repeated, often using fresh materials for the next set. A random sample of film employees would not be expected to be any less environmentally conscious than the general population, so one wonders if there is something about the film production process itself that encourages or facilitates this behaviour.

In the last few years, however, awareness of sustainability issues has infiltrated the previously insular world of film and television production insulated, because it was only in 2006 that the first publicly available report, made by a UCLA team of researchers, was published in which an attempt was made to identify and quantify the environmental impacts of screen production (Corbett and Turco 2006).

A brief review of the existing academic literature reveals that there is a dearth of relevant research that evaluates long established environmental management techniques within the context of film and television production. What does exist, however, is a number of consultant reports that various film production jurisdictions have commissioned in an effort to position themselves as environmentally friendly filming destinations. These reports have opened the discussion on film sustainability by making efforts to quantify emissions, to present employable strategies, and to develop working tools to assist productions.

While sustainability is now a subject of discussion in the industry, with a number of studios and independent productions now making efforts in this area, "obvious industry wide rules and standards suggest that the FTI [film and 
television industry] as a whole has yet to devise effective approaches for implementing progressive environmental practices" (Corbett and Turco 2006, p. 40). Certification options are increasingly available, but none has yet achieved a significant market penetration. What is preventing the industry overall from seeing a broad uptake in these practices, or the industry wide adoption of a gold performance standard? While there has been progress, can it be said that there is a real momentum behind the efforts, such that sustainability is or will soon be a given on any production? If not, why not?

This research seeks to determine if there are drivers and barriers to environmental management that inherently exist as a result of the organizational structure of the film production industry, which is project-based. Those barriers have made it challenging to adopt universal environmental practices, and the drivers have not provided sufficient motivation to overcome them. Unlike the construction industry, which is presented as a parallel industry in structure, but one with a more robust and embedded environmental management ethic, the film industry is struggling.

\subsection{Purpose}

The purpose of this research is to examine the current state of the film industry's environmental management efforts, by using the temporary structure of the production itself as a framework. For the purposes of this research, "film" is synonymous with "motion picture", and in keeping with Corbett and Turco (2006), includes both the film and television production industries. Environmental management is defined from Bansal and Roth (2000) as the initiatives designed and implemented to mitigate an organization's environmental impacts. In the context of film, "sustainable production" is limited to environmental considerations alone, and is the application of environmental mitigation strategies during the period of film production.

Film productions occur over a matter of weeks and months. The principal contribution of this research is that the limited duration of this organizational 
entity - the project-based organization (PBO) - is the primary means of evaluating the nature of both the barriers and drivers to successful sustainable film production. A "project-based organization", also referred to as a "projectbased enterprise" in the literature, is defined as a set of individuals working together on a complex task over a limited period of time (Grabher 2002a; Goodman and Goodman 1976).

It is anticipated that by first identifying the major drivers and barriers specific to environmental management in the film industry, and then performing a SWOT analysis framed in the context of the project-based organization and utilizing the construction industry comparison, it will be possible to understand certain aspects of the environmental management efforts of the film industry. First, what motivations exist for the project-based organization to expend resources to implement an environmental management program? Second, do the barriers identified for the film industry align with those that are predicted by a review of the project-based literature, and with those experienced by the project-based organizations in the construction industry?

The following will serve as gateway objectives in this research:

- What are the strengths, weaknesses, opportunities and threats in implementing environmental management on a film production?

- How do the identified weaknesses and threats relate to the projectbased organization structure in the film industry?

- What strengths, weaknesses, opportunities, and threats exist in implementing environmental management in the construction industry? How do those compare to the film industry? 


\subsection{LITERATURE REVIEW}

A literature review was conducted on three fronts: on the theory of projectbased organizations, on the environmental management practices of the film industry, and those of the construction industry. Importantly, this review will also begin to frame answers to the questions as to the relevance of this study, and the potential research opportunities that may be asked subsequently.

\subsection{Project-Based Organizations}

The first goal of the literature review is to answer the question of what "project-based enterprise" is, and why film production might be considered an example of such an enterprise. Further, the literature that pertains to the comparator industry of construction is explored, to situate that industry within the same "project-based" context.

The literature on the project-based organization is abundant, and fortunately includes a number of articles that deal specifically with the case of the film industry as an example of the project-based firm. Compiling a complete inventory of the themes in this area was not necessary, so the review concentrated on the concepts most germane to the research. The importance of these concepts relates to the question of how to embed knowledge in temporary organizations, and may help ultimately answer the question of how to institutionalize environmental management practices in a film production. This section also looks at some of the gaps in the literature, as while the concept of a PBO is not new, and is subject to increasing interest in the academic community, it has not been entirely developed. In exploring the literature and theory of PBOs, the approach is to review the general theory first, and then to address the specific case of film production.

Miles (1964) first identified the concept of a temporary organizational system. Miles' initial conception of this organizational form extended to a diverse array of systems that included juries, games, research projects, and even legislative 
sessions and love affairs (Miles 1978). What these systems have in common is that their duration is different from a traditional, enduring organization (Miles 1964).

Developed industry examples that have utilized a project-based approach ones that may assemble independent or unrelated individuals (i.e., contractors) into a temporary team - have been identified in the existing literature, and include among others: advertising (Bayer and Gann 2007), film productions (Jones and DeFillipi 1996), construction projects (Eccles 1981), and engineering (Bayer and Gann 2007). Examples of the outputs of the project-based form include intelligent buildings, computer integrated manufacturing systems, avionics systems for aircraft, all of which are customized and complex systems (Hobday 2000). Other examples include feature films and finished buildings. The PBO structure has been identified as one that is highly conducive for "managing increasing product complexity, fast changing markets, crossfunctional business expertise, customer focused innovation and market, and technological uncertainty" (Hobday 2000, p871).

Most importantly, from Miles (1964), is to note the time constraint that is the key characteristic of the PBO. In contrast with a traditional theory of strategic management, which defines the survival of the firm as an objective, even a successful PBO will have an expiry date (DeFillipi and Arthur 1998). The goal of the PBO is not to endure, profitably or otherwise; oftentimes, its goal is only to deliver an end product. Upon delivery of that product, the PBO dissolves. Employees dissipate, organizational structures are disbanded, and assets are sold off or returned to the parent entity that initially commissioned the project.

\subsubsection{Core Competencies, Knowledge Transfer, Innovation}

The core competencies of corporations are the "collective learning" (Prahalad and Hamel 1990, p82) of the organization. This organizational knowledge is what allows organizations to problem solve and even to innovate (Miner and Mezias 1996). Perhaps most critically, the ability of the enduring organization to 
innovate ultimately results in competitive advantage (Barrett and Sexton 2006). Competencies are more than just knowledge, and there are well-documented mechanisms, such as assets, rules, and routines, by which these competencies are embodied and transferred in the enduring organization (Ferriani et al. 2005). These are the retention devices that allow organizations to remember, and thereby suffer the loss of individual employees, among other issues, without also losing knowledge (Ferriani et al. 2005).

Traditional organizational theory assumes the continuity of the firm as a precondition to developing and institutionalizing core competencies (Prahalad and Hamel 1990). Of particular interest then, to the project-based organization, is the manner of collection and utilization of those competencies given its fixed life span includes a predetermined dissolution. With time as a constraint, and perhaps just as importantly, with the demise of the project both certain and scheduled, what mechanisms are available for the development and the transfer of these competencies? The risk when discussing innovations in the form of novel techniques and strategies in a project-based organization is that the knowledge may be lost on the dissolution of the organization, resulting in an "organizational amnesia" (Grabher 2004, p1492). In this research case, that new knowledge or competency is environmental management techniques within the film industry; the literature does address this question in general.

Time and cost have been identified as barriers to innovation within the project-based organization (Salter and Gann 2003). The development of new capabilities is a precondition for adaptation to a shifting environment (Bayer and Gann 2007), and opportunities to develop innovative problem solving - whether strategy or product development in the case of environmental management - are simply not prevalent (Bayer and Gann 2007).

Innovation is needed for survival and competitiveness. As Bayer and Gann (2007) note, the development of these techniques would typically occur during the project execution phase of an enduring organization. However in a project- 
based organization, where time and cost constraints restrict project participants to implementing the most cost effective output possible, there is no research and development period available within which those capabilities are typically developed.

Time constraints can also prevent an organization from documenting project knowledge, resulting in the loss of that knowledge upon dissolution of the organization (Bayer and Gann 2007). Newell and Edelman (2008) observed that to facilitate knowledge transfer between projects some form of codification needed to occur. It is an intuitive hypothesis: that new knowledge needs to be experienced or developed, then articulated, and finally documented to maximize the potential for its use in a future project. Interestingly, the study also observed that both of these codification precursors - experience and articulation - are on their own insufficient to ensure that knowledge transfer may occur. The critical success factor is the resultant document that becomes available to a subsequent project team (though one imagines that there exist other potential success factors, such as the transplant of key personnel that embody that knowledge). Importantly, there still exist barriers related to the uptake of that information, as the new project team may lack certain skills, personnel, or background knowledge for them to capitalize (Newell and Edelman 2008).

Phelan and Lewin (1999) note quite simply that a PBO is not able to accumulate core competencies due to its temporary nature. DeFillippi and Arthur (1998) agree, arguing that core competencies are in fact embodied in the human capital of a project - that is, in the employees themselves. To begin to embed a new innovation then, a PBO needs only to secure the key employee that holds the desired knowledge. The issue of innovation and knowledge transfer is perhaps then both a casualty and a consequence of the fact that project participants are mobile.

\subsubsection{Social Context}

In a comprehensive study of the existing project-based literature, Bakker 
(2010) identifies four key concepts that help define a PBO: time, team, task and context, each of which offers its own degrees of variation. Time, of course, refers to the duration of the PBO, which is at a minimum, "different" (Miles 1964) from other organizational forms. The concept of a team is the collection of skills, human resources, and the overall interdependence of the PBO's members (Bakker 2010). Task is that which the PBO has been assembled to execute (Bakker 2010). Context is the various forms of connection a PBO has to the enduring environment in which it is embedded (Bakker 2010). While Bakker's analysis offers a number of relevant lines of inquiry in relation to film, it is the context theme that may be most productive for this research.

Grabher (2004) supports a view of the PBO as being embedded into two broader contexts: a "firm-level" context and a "social" context. At the firm level, a PBO may be the creation of an enduring organization for some specific purpose, and in which it is embedded (Bakker 2010). The social context is provided by the broader industry in which the PBO may be situated, and the enduring personal relationships that influence the PBO (Bakker 2010). It is the idea of a social context that will be explored further here, as we are concerned with the connection the film PBO has with the industry at large (and its various groups), and with its ultimate parent company (i.e., the studio).

Ferriani et al. (2005) argue that organizational learning in the film industry case is made possible through patterns of collaboration. These patterns are repeated as project team members have ongoing, if segmented, personal and professional relationships resulting in a so called "latent network" (Ferriani et al. 2005). This network may provide the learning mechanisms evidenced in enduring organizations, and that otherwise seem to be lacking in project-based ones (Ferriani et al. 2005). The "latent network" of personal relationships described by Ferriani et al. (2005) may form an aspect of the "social context" of Grabher (2004).

Bechky's (2006) proposal is that the project-based organization (in this case 
the film production) is structured around enduring role systems. The continual reproduction of these role systems is what allows the PBO to maintain continuity across projects (Bechky 2006). Where traditional organizations would rely on the permanent structures available to them - such as rules and hierarchy - to coordinate activity, PBOs will instead rely on role structure and emergent practices (Bechky 2006). In Bechky's (2006) analysis of the film industry, she argues that role structures allow the film industry's temporary employees to understand employment expectations and work routines. Once trained and familiar with the role structure, in other words, a crew member is able to step into a new production and immediately perform their duties.

The structures provide employees with continuity across the temporary organizations that comprise film production (Bechky 2006). Project teams groups of individuals who are employed by the PBO - often work together on successive projects (Ferriani et al. 2005), and thus endure beyond of the PBO itself in a social context (Bechky 2006). So while a production company may be temporary, there are elements of permanence suggested by Bechky that support Ferriani et al.'s proposition, and that serve to replicate the learning structures in enduring organizations.

A project-based organization is not an isolated effort devoid of context (Engwall 2003), as we have seen, but can also be considered couched within a broader industrial context (among many other possible contexts, i.e., cultural). Projects, despite their temporary nature, are certainly influenced by the social relationships that develop with them, but also by the social relationships that flourish outside the PBO boundaries and within the broader industry at large. This is not difficult to apply to the film production. For example, many film production companies are sub-entities of the major film studios, in which temporary agents in the PBO may have enduring relationships with the permanent employees in that parent entity. DeFillipi and Arthur (1998) also note that the professional guilds and unions endure outside of the temporary production companies, and have their own structures, including educational 
ones. Their existence offers a form of permanence for the temporary employees in which relationships can be formed, developed, and of course, dissolved.

Importantly, there is the possibility of organizational continuity within these temporary film production companies. While Bechky (2006) notes the sample size limitation in her research, there is less uncertainty around the fact that the role structures she discusses are industry-wide in application, in that the various positions within a film production in Toronto line up very closely with a production in Los Angeles. What becomes an important topic for discussion then is the availability of a consistent, industry-wide structure in which the institutionalization of environmental management practices could be the goal. If environmental management can be made to work successfully in Toronto, it should then also work in Los Angeles. While Grabher (2004) does not perform a detailed analysis of the film industry, he believes this category of work may qualify as a "network based" ecology, one in which the knowledge repositories are located solely in the personal networks.

There is apparent support in the project-based organization literature, and the film case specifically, that organizational learning may be available in the form of the social context, or latent network of employee relationships. However, Newell and Edelman (2008) note that any effort to build a competence by relying solely on the accumulating experience of industry personnel - without resultant articulation and codification - may have a structural deficiency. While this is very much the general case, there may in fact be additional barriers if that learning is an environmental management competency, or occurs in the film industry case specifically. On this the literature is silent, and where this research may make a first contribution.

\subsubsection{Research Gaps}

Despite a surge in recent years in the number of articles devoted to projectbased enterprise, gaps still remain in the research. Hobday (2000) is straightforward in saying that "there has been little research on... how the PBO actually 
operates in practice" (p. 872). Bakker (2010) brings together the research on the topic to identify resultant deficiencies, and notes the dominance of conceptual (as opposed to practical) studies with respect to studying the salient characteristics of an organization and what defines it as temporary. Bakker identified the four themes emergent in the PBO literature (of time, team, task and context, discussed previously), and noted that the research on each of those themes has gaps. For example, on the question of time, it was noted that the duration of PBOs varies from days to years - so when does an organization still qualify as being temporary, and what are the implications of the range of variation that exists?

\subsection{Construction as Project-Based Enterprise}

The construction industry, like the film industry, is presented in the literature as an example of project-based enterprise (Hobday 2000; Bakker 2010; Ferriani et al. 2005). This section will briefly review the reasoning behind this categorization, and explore some of the industry's environmental management efforts. The question of innovation in construction, already reviewed in the general case, will also be addressed.

The complexity involved within a construction project is highly visible. Walking by a building in mid-construction reveals a tangle of steel, concrete, materials, and people. To the uninitiated, there is little order apparent - it may have the appearance of chaos. This layman's interpretation is supported through the literature, including the statement by Winch (1987) that construction projects are amongst the most complex of all undertakings.

Cox and Thompson (1997) argue that traditional supply chain models do not apply to the construction industry, since "repetition is rare and works are procured typically on a one-off project-by-project basis" (p. 128). Construction projects too, by their nature, are temporary in duration. The complexity and temporary nature of construction then, align very well with Grabher's definition of the project-based organization provided above. 
A productive line of inquiry for a construction PBO has proven to be the idea of a "quasifirm" (Eccles 1981). The construction quasifirm results from the stable and continuous relations between a general contractor ("general") and its subcontractor ("sub") (Eccles 1981). Over the course of a number of successful projects, the general and its subs are able to achieve some measure of efficiency by having developed an ability to work together (Eccles 1981). This can be realized in a number of ways: for example, the general does not necessarily need to tender jobs to a vast set of subcontractors for every project; conversely, the sub is not always bidding a job against numerous competitors (Eccles 1981). The relationship is strengthened, too, by the ability of both parties to be able to reconsider the terms of their relationship with every new project; or to dissolve the relationship, and test the market and work with a new partner (Eccles 1981).

\subsubsection{Innovation}

An interesting observation made of the project-based construction organization is that there is a great deal of resistance to change (Kadefors 1995). For a project-based organization to have such resistance, Kadefors argues that there must be a strong institutionalization present. Institutions, in this context, are power relations and control systems; they are socially constructed, and continually reproduced; they are organizational forms, structural components, and rules (Kaderfors 1995). In other words, they are a way of doing things, or "the embodiment of organizational learning" (Stinchcombe 1985, p. 134).

Barrett and Sexton (2006) ask the next - and key - logical questions: For the project-based organization, what motivation exists to innovate at all? What might common results of innovation be for these firms? Are innovation processes behavioural or rational in nature?

The answers the researchers find to those questions are interesting. With respect to motivation, Barrett and Sexton (2006) find that project-based organizations are not always motivated to innovate, as the cost and risk may be limited if the firm is just struggling to exist. Arguably, this is something that may 
be true of all organizations. With respect to results, innovation is focused on improving the ability of the organization to get repeat business (Barrett and Sexton 2006). A Darwinian type selection is almost implied: innovations that do not serve the goal of improving the odds of survival are unlikely to be adopted or maintained.

The study's findings also indicate that the actual process of innovation in small project-based construction firms is predominantly behavioural (Barrett and Sexton 2006). The desired performance is achieved through the perseverance of action forces (or drivers), such as availability of resources and management support, and thereby overcoming any reactionary forces (or barriers), such as employee resistance and lack of embedded processes and workflows. Hartmann (2006) identified key success factors for those construction companies that succeeded in innovation: an ability to innovate via resource availability, and a willingness to innovate driven by corporate culture and individual behaviour in applying those resources towards the goal of innovation.

The current research offers an excellent frame of reference for an analysis of the film industry's efforts to inculcate an environmental management ethic in its production practices - an innovation, to be sure. The same questions then needs to be asked: What motivation exists for the film industry to 'go green' (or innovate sustainable production practices) at all? What innovation results might be expected, or have been seen? What are the drivers and barriers that have been identified thus far?

\subsubsection{Green Innovation}

Literature on environmental management, which is limited in availability in the context of the film industry, does exist for the construction industry. Of interest then is whether some of the discussion that is presented in the existing literature might be applicable to film.

Gluch et al. (2009), discussing green innovation in the construction industry, note that despite the development of green building practices and analytical 
environmental management tools to guide practitioners, mainstream building practices remain largely unchanged. Corbett and Turco (2006) argued similarly of the film industry. Gluch et al. (2009) also indicate that even companies with advanced environmental management systems tend to focus on a few targeted measures; meaning they did not seem to be using an approach that would ultimately drive innovation forward. The literature from the film industry also presents limited variation on a common set of focus areas: waste management and carbon emissions (see Felder et al. 2008, Corbett and Turco 2006, NZ MOE 2005).

There is good news for the film industry, if the construction analogy holds. Gluch et al. (2009) state that previous research on innovation in sustainable construction practices revealed that increased corporate focus on green innovation in the construction industry raised project quality, sustained the overall position of the companies within the industry, and had relationship strengthening features for the employees involved. What they saw was the emergence of competitive advantages from the use of green practices. Competitive advantage in the area of environmental management is the stated goal of a number of filming jurisdictions (Felder et al. 2008). The logic being that having a robust environmental management program in place is one more reason for a studio to bring their lucrative filming dollars to a certain filming location.

The body of project-based construction organization literature provides a number of analogies to the project-based film industry: in seeming complexity, with the idea of the quasifirm, and innovation. Taken together, these offer a measure support for the use of construction as a comparison industry. Despite the fact that very little academic research exists for environmental management in the film industry, there is a comparable body of literature for this field in the construction industry, which may be partially transferable.

\subsection{Film as Project-Based Enterprise}

The UCLA study by Corbett and Turco (2006) was not just a landmark study 
for making an effort to quantify environmental impacts associated with the film industry, but it also suggested the importance of the project-based nature of film, and that any environmental management model developed for this industry may have broader application in other project-based industries. This research is concerned with the opposite case, or the transfer of any lessons learned from other PBOs to the film case.

Corbett and Turco (2006) were not the first to characterize film production as being a form of PBO. DeFillipi and Arthur (1998) identify some of the general characteristics of the PBO evident in film productions: the entity is directed in its goals and methods, rather than being self-defining; there is a specific end result in mind, namely a product; funding is allocated, and there is not an expectation for the entity to generate any form of income. Whether a studio or independent film, a production is assigned or is otherwise working within a fixed budget with the goal of completing a single task: to deliver a film negative (or its digital equivalent) to the studio or financier. The characteristics of the PBO are also evident in the fact that labour and physical assets are both temporary (DeFillipi and Arthur 1998).

Phelan and Lewin (1999) reaffirm the temporary nature of film productions, but also believe that prevailing strategic management theories explain their existence quite satisfactorily. The presence of independent production companies in the film industry are simply the result of demand uncertainty for screen productions. The studios, the authors rightly argue, citing resource-based theory, have outsourced production to these temporary production entities in order to maximize flexibility. The studios gain the ability to "combine resources in novel ways to try and create a hit movie" (Lewis and Phelan 1999, p183), and that the completion of a project is a convenient evaluation moment for various project participants.

The quasifirm concept of Eccles (1981) lends itself well to the film industry. Bechky (2006) describes a film set using a similar concept, one of a "total 
institution" (Bechky 2006, p10), which is a place of work (or residence) where similarly minded people are temporarily isolated from society (Goffman 1961). To compare, a department within the film production company is akin to the subcontractor on a construction project, in that it is often composed of a group of people who work together repeatedly, effectively becoming a team. Different departmental teams are then often repeatedly reassembled together onto new projects. A quasifirm could arguably develop through the continuous interaction of these teams, providing the same attendant benefits (i.e., efficiencies). There are potential cost savings available through established relationships, as there is an incentive from the subcontractor - or film departmental team - to procure new work upon the fixed deadline of dissolution of the existing project (Eccles 1981). Eccles (1981) and Bechky's (2006) research raises similar arguments within the two different industries under consideration, offering a measure of support for the basis of comparison used in this research.

Corbett and Turco (2006) use the PBO model to suggest that the challenge facing the uptake of sustainability for film productions may lie in their temporary, or project-based, nature. The literature just reviewed tells us that there are intrinsic barriers in the project-based organization structure, in the form of time and cost. Those barriers make it difficult to innovate, to develop new competencies, to document and then to share that acquired knowledge across projects. In addition, DeFillippi and Arthur (1998) identify the barrier of movable project participants on film productions, who embody the knowledge that may or may not be documented.

Motivations are also a relevant question for the PBO. Bansal and Roth (2000) identify three basic drivers for ecological responsiveness in corporations: competitiveness, legitimation, and ecological responsibility. These drivers can also be thought of as: long term profitability, long term survival, and social obligation (Bansal and Roth 2000). The organizations under study that revealed these motivations were not PBOs, but their permanent brethren. Given long term motivations are not a driver for a $\mathrm{PBO}$, one wonders if the environmental 
management drivers for film production companies, and possibly for PBOs in general, differ from those seen in permanent organizations.

\subsection{The Structure of the Film Industry}

By any account, the film and television industry is big business. Global box office results for 2011 reached $\$ 32.6$ billion, with $\$ 10.2$ billion coming just from the domestic markets of Canada and the United States (MPAA 2012). As a measure of GDP, the motion picture and sound recording industry produced $\$ 60.2$ billion worth of the GDP of the United States in 2011 , or about $0.4 \%$ of the nation's total (U.S. Bureau of Economic Analysis 2012).

The "major" studios are the six dominant entities in the production and distribution of motion pictures in North America. Together they release over two hundred films per year and generate some ninety percent of the industry revenue (Greenwald and Landry 2009). Those studios are (Greenwald and Landry 2009):

- Sony Pictures,

- $20^{\text {th }}$ Century Fox Films,

- Universal Pictures,

- Warner Bros.,

- Paramount Pictures, and

- Walt Disney Pictures.

The "major" studios are now all subsidiaries of much larger conglomerates; and in turn, each typically owns a specialty division that produces low budget "independent" productions (Schatz and Perren 2004). Multiple sources have described the current industry structure as an oligopoly (Schatz and Perren 2004, Greenwald and Landry 2009). At an average cost of $\$ 71$ million per film, and with a typical slate of twelve to fifteen films per year, production costs at each studio can be as high as $\$ 1.3$ billion in any given year (Greenwald and Landry 2009). 
The structure of the film industry can be broadly categorized into three sectors as seen in Table 1.

Table 1

Film Industry Sectors

\begin{tabular}{ll}
\hline Production & The process of making a film. \\
\hline Distribution & $\begin{array}{l}\text { Licensing or sale of a completed film to } \\
\text { various media outlets (e.g., theatres, } \\
\text { television networks, marketing activities). }\end{array}$ \\
\hline Exhibition & Delivery of the film to the consumer. \\
\hline Adapted from Greenwald and Landry (2009).
\end{tabular}

As this research is focused on the Production sector of the industry, no further exposition will be undertaken for the Distribution or Exhibition sectors.

The Production sector can itself be loosely broken down into stages, which include: Development, Pre-Production, Production, and Post-Production. The full life cycle of a film would also include the Sales and Distribution stages (see Felder et al. 2008a), as well as Exhibition. The specific tasks in each stage vary according to the size of production and entities involved (i.e., a small web video versus a large Hollywood blockbuster). Some of the key tasks that are involved in each stage are identified in Table 2.

Prior to the physical act of shooting a film, there is a Development process that occurs which assembles all the key components required for production: director, talent, key crew members, script, and critically, financing. There are a number of different financing mechanisms available to producers. Financing can come directly from a major studio, or be split in some manner with the producer's company. An independent producer, on the other hand, may need to find private financing (banks, investors) or by pre-selling the distribution rights to the picture. A combination of all of these mechanisms is also a possibility. 
Table 2

Stages of Film Production

\begin{tabular}{ll}
\hline Development & $\begin{array}{l}\text { Script development, assembly of key talent, } \\
\text { financing arrangements, budgeting. }\end{array}$ \\
\hline Pre-Production & $\begin{array}{l}\text { Planning the actual shoot, including location } \\
\text { scouting, scheduling, set construction, } \\
\text { storyboarding, rehearsals. }\end{array}$ \\
\hline Production & $\begin{array}{l}\text { Principal photography - the actual shooting } \\
\text { of the movie. }\end{array}$ \\
\hline Post-Production & $\begin{array}{l}\text { Editing, visual effects, sound effects, title } \\
\text { and end title sequences. }\end{array}$ \\
\hline
\end{tabular}

Adapted from Greenwald and Landry 2009.

Once a film is greenlit (approved for production and financing made available) it enters into the Pre-Production stage. This is where the physical elements are prepared for filming (sets, locations, costumes, props) and a shooting schedule is developed. This leads directly into the Production stage, when the movie is shot. Filming takes place both inside and outside (on location) of the controlled environment of the production studio. All of the major studios own production facilities, that when not in use for their own films are rented out to other productions. Jurisdictions across North America and the world all compete through a combination of tax incentives, location requirements, and crew strength to be chosen as the filming destination for a production.

\subsubsection{Formation of the PBO}

Once the filming location is chosen, a separate legal entity (typically a corporation or limited liability partnership) is formed in that location as a subsidiary to the studio for the dedicated purpose of producing the film (Greenwald and Landry 2009). This entity is the project-based organization, and can exist for the entire duration of the Production sector of the filming enterprise. The major studio behind the film acts as a fiduciary parent to the new PBO, 
providing funding for the project. The PBO will also make use of standing resources at the studio (such as legal and executive functions). Filming may also occur on the parent's studio facilities, but can also occur at another major studio's facilities (these resources are treated as a commodity, and physical filming locations are determined by availability, location, cost, among other factors). The parent studio always retains the ability of being able to shut down filming - and thus terminate the PBO - at any time.

From a management perspective, the producer and the director are the key executives in the new PBO, and the ones who select and hire the balance of the cast and crew. These talent positions would have been selected by studio executives, although their contracts would typically run through the new PBO. The remaining crew members come "from the outside" (DeFillippi and Arthur 1998, p. 129), are mostly from the local community, and would have no interaction at any level with the studio. Employees will typically work for a period of weeks or months until filming is complete. Crew size will start at zero at the company's inception, reach a maximum at some point during filming, and then dwindle again until the company is ultimately dissolved, upon completion of its primary objective of delivering a completed film.

When shooting is completed (but often during the actual filming), PostProduction occurs. This is when editing, visual effects, and sound effects (among other tasks) are performed.

\subsection{Environmental Management in Film Production}

In reviewing the available literature on environmental management practices available and in use in the film industry, it was discovered that there was scarce reference in academic, peer-reviewed sources such as journals. Necessarily, then, the scope of documents considered was expanded to include environmental consultant and film commission reports, self-published sustainability guides, newspaper and trade publication articles, and industry environmental non-governmental organization websites. This resulted in an 
expanded set of documents, although the overall quantity available did suggest that discussion of the topic was still in its infancy. The specific lack of academic articles is one area where this study may begin to offer a contribution both as a publication in its own right, and by identifying potential areas of future research. The review did examine the nature of the environmental impacts and types of mitigation strategies available for film productions, the empirical studies that have been performed in an effort to quantify emissions associated with film production, and the drivers and barriers to implementation that were presented both explicitly and implicitly.

\subsubsection{Environmental Impacts of Film Production}

The nature and magnitude of the environmental impacts associated with film production have been discussed in many of the recent jurisdictional reports. However, it was not always evident just how significant a polluter the industry is, or where those impacts are being generated.

The sustainability report on the film industry by Corbett and Turco (2006) was the first readily available academic study that makes an effort to identify and quantify the environmental impacts associated with motion picture production in Los Angeles (i.e., Hollywood), and at the state and national levels. The analysis compares the selected impacts of air pollutants released, energy consumption, greenhouse gas emissions, hazardous waste and fatalities from film production to other industries with significant emissions in California (aerospace, petroleum refining, apparel, hotels, and semiconductor manufacturing). The limitations of the analysis includes a lack of verification of self-reported values; and, as the study itself indicates, the results at best only provide "relative orders of magnitude" (Corbett and Turco 2006, p18) for the industry sectors under consideration. The study uses the Economic Input-Output Life Cycle Assessment (EIOLCA) method to estimate impacts associated with each of the sectors under study. This life cycle approach attaches a total economic output value for each one dollar of final output in the industry under study. The method then uses emissions coefficients for each sector of the total economic output to generate 
emissions estimates.

The results indicate that the primary environmental impacts of the motion picture industry are associated with energy usage, and were of a comparable order of magnitude to those of the aerospace, apparel, hotel, and semi-conductor industries (Corbett and Turco 2006). In fact, all impacts under consideration produced similarly scaled results. One conclusion drawn by the study is that the California film production industry is a significant polluter, and the impacts are of a relative size to the comparator industries. For example, at the state level, the motion picture industry releases 140,000 tonnes of criteria air pollutants per year. The apparel industry releases 155,000 tonnes, the semiconductor industry 210,000 tonnes, and 85,000 tonnes for the hotel industry. Petroleum refining dwarfed all the categories by releasing 550,000 tonnes per year (Corbett and Turco 2006). One result of the study, even with its limitations, was that the film industry could no longer claim ignorance of the fact that it had significant environmental impacts associated with its activities. The question remains whether it has taken that result to heart.

The study also exposed the fact that while the industry was interested in using its high profile platform to present issues of environmental importance on screen, that interest had not yet been reflected within its internal operations: "the lack of obvious industry-wide rules and standards suggests that the FTI [film and television industry] as a whole has yet to devise effective approaches for implementing progressive environmental practices" (Carlson and Winer 2006, p40). In its very recent history, then, this high profile industry was noted for having serious environmental impacts, and no formal strategies towards mitigating those impacts.

Felder et al. (2008a), in the Green Screen Environmental Assessment, identified the following categories of environmental impacts at the production level:

- Solid waste (paper) from the printing of scripts and schedules; 
- Solid waste (wood, metal, plastics, paints) from the building of sets;

- Fuel consumption and GHG emissions from the production vehicle fleet, which includes: cars, vans for cast members, cube vans, panel vans, and full sized tractor trailers;

- Food (compostable materials) and solid waste from disposable packaging and service materials (Styrofoam, plastic, non-compostable items) through craft services and catering;

- Fuel usage and GHG emissions from generators used to remotely power production shoots on location;

- Electricity consumption in studio, for set lighting and office;

- Natural gas consumption, for studio heating.

The study by Felder et al. (2008a) takes another approach to quantifying the environmental impacts associated with film production, and differentiates between small, medium, and large feature films and television series, as based on budget size, number of shooting days, and number of employees. Where Corbett and Turco's (2006) study uses the EIOLCA method, the analysis by Felder et al. (2008a) combines qualitative and quantitative data gathered through a variety of means, including expert interviews, site visits, and industry meetings. The analysis produces startling figures for these listed impacts. Paper usage, on a feature film or large television series, is estimated at 810,000 sheets; over 900 tonnes of construction material will be consumed on a large feature film; up to 175,000 litres of gasoline consumed in a large television series, and a staggering 100,000 plastic water bottles for a large feature film (Felder et al. 2008a). The authors do caution that the results of the assessment provide insights, but cannot be considered a statistically significant quantification of industry environmental impacts.

The assessment by Felder et al. (2008a) defines a similar structure for the life 
cycle of a film production by labeling five phases: Development, Pre-Production, Production, Post-Production, and Sales and Distribution. The assessment's analysis is then constrained to just that portion relating to the Production phase, as it is deemed to be the phase with the greatest level of impact, as represented by Figure 1, which shows generally the levels of environmental impact over the course of an entire life cycle of a film production.

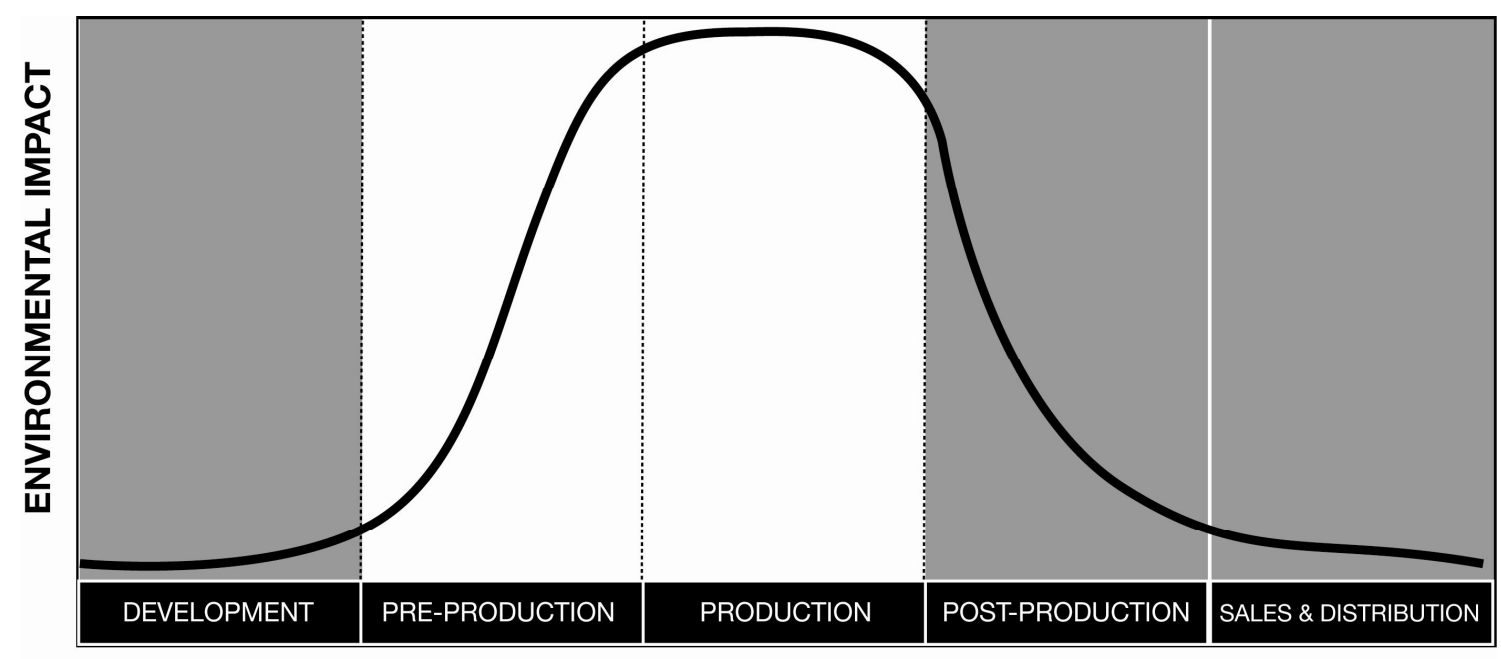

STAGES OF PRODUCTION

Figure 1. Life Cycle Phases of a Film Production. Adapted from Felder et al. (2008a).

It is worthwhile to note that the level of impact represented in the graph likely correlates quite closely to the staffing levels on a production, making the level of environmental impact at any one time a function of the number of employees. The approach of focusing on the production phase by Felder et al. (2008a) was also driven by the number of readily available production entities in Toronto in that specific phase of their life cycle (as the Development, Post Production, and Sales and Distribution phases for any United States studio production are very likely to occur in the United States).

By design, though not at this stage explicitly stated, the study by Felder et al. (2008a) has targeted the temporary production entity - the project-based enterprise or organization - which is, being argued here, of critical importance in 
framing the discussion around environmental management for the film industry.

\subsubsection{Environmental Mitigation Strategies}

There is evidence that grassroots efforts were being made at environmental management in the early 1990s. Fessenden and Ellenbogen's (1991) work in this field yielded a self-published guide on low impact filmmaking; but it did little to shake up the industry's way of doing things, as Corbett and Turco's (2006) warning bell study fifteen years later shows.

Just a year before Corbett and Turco's study, the New Zealand Ministry of the Environment (2005) (NZMOE) published an environmental "toolkit" called Greening The Screen for use by screen based productions to manage their impacts. In three sections, the toolkit presents the business case for corporate environmental management, steps to identify and manage environmental impacts associated with film production, and a set of environmental tools to assist the environmental manager (NZMOE 2005).

Mitigation strategies for the environmental impacts of film production are available in many of the published guides. To address paper waste, for example, Greening The Screen suggests printing scripts on demand only, using electronic documents, printing double sided documents, recycling used paper, and using paper that already contains recycled content.

The British Columbia Film Commission has published a set of "Environmental Best Practices" under an initiative called Reel Green on their website (British Columbia Film Commission 2011). Substantially similar in format to the Toronto initiative, the BC effort acknowledges the Greening The Screen publication as a source of some ideas presented on the site. To address the waste generated by construction activities, for example, the suggested best practices include donating unwanted set materials to theatres and high schools, using environmentally friendly paints, and using recycled or sustainably managed wood over virgin stock. 
The Green Practices Manual by Felder et al. (2009) builds on their Environmental Assessment (2008a), and builds in a cost savings estimate for their mitigation strategies to assist in preparing a business case for environmental management. For the impacts associated with the use of production vehicles (fuel usage), this guide suggests encouraging the use of biking, walking car pooling, and public transit as transportation options, using biodiesel as a fuel alternative, sourcing hybrid and fuel efficient vehicles, and have an anti-idling policy in place.

Greening The Screen was the first jurisdictionally-based environmental practices manual, and is designed to promote New Zealand's film production community as a leader in environmental sustainability (NZMOE 2005). This format - i.e., regionally based sustainability initiatives - was quickly adopted by other film production jurisdictions, all of which recognized a potential competitive advantage in offering green production values.

The regional character of these publications is important, as they are clearly designed to promote their respective jurisdiction as a filming destination as one that is able to provide leading sustainable production practices. The aim appears to be an attempt at potentially gaining a competitive advantage in attracting business. The funding sources for their development are also similar, being local environmental consultants engaged through government grant money. The Green Screen Toronto (Felder et al. 2008a) publication was funded by the Ontario Media and Development Corporation, an organization whose mandate is to "promote[s], enhance[s], and leverage[s] investment, jobs and original content creation..." (OMDC n.d., para. 1). The Environmental Assessment echoes this, stating that "consideration of how to attract and retain American business is critical to the success of any Industry-based initiative" (Felder et al. 2008a).

The development of toolkits has been a jurisdictional effort, and usually involves the creation of a green production guide. A guide typically includes a review of suggested environmental strategies broken down by the different 
departments on a film shoot, such as, recommending that the transportation department rent hybrid vehicles to reduce fuel consumption and related emissions (NZMOE 2005), or the production office distribute scripts digitally to reduce paper consumption (Felder et al. 2008a). A production guide can also come paired with a companion resourcing guide, which facilitates locating required products and service providers in the filming jurisdiction.

The Producers Guild of America has also assembled a best practices list and green resources guide. The initiative was funded with seed money from seven studios, and has also yielded a mobile app (Producers Guild of America 2010). There is an implicit bias that should be noted simply based on the funding source, as the efforts may be specifically tailored to represent studio interests. However, the level of cooperation seen at the studio level, likely between the sustainability departments of each of the represented studios, is encouraging.

While each jurisdiction mentioned has produced its own set of green production strategies, certainly each independent environmental consultant hired by a production will come armed with a version of the same. With the proliferation of these production guides in so many jurisdictions now, there is inevitably duplication in the presented strategies. One question that arises is whether one version (or combination) of these guides will in effect become the standard to which all productions eventually subscribe. If there is an agreement on the strategies to be implemented, there may then follow a movement towards a definable environmental certification.

\subsubsection{Certification Options}

The push for improved environmental management practices in the film industry has led to the development of a handful of certification options. Some jurisdictions have recognized the potential marketability associated with having a branded, exportable certification standard (Felder et al. 2009). Of greatest interest, is what role a certification standard might be able to play as a driving force towards improved environmental management. 
Corbett and Turco's (2006) study notes that the American Humane Society familiar "No Animals Were Harmed" certification of film productions was one that could be used as a model for environmental performance. It is well known in film (and audience) circles, and has obtained the required industry buy-in to be recognized as the only standard against which animal handling claims may be measured (Corbett and Turco 2006).

Industry wide, there are but a handful of available options for measuring and acknowledging environmental performance. The Environmental Media Association's Green Seal is the oldest and most recognized program in the industry. The UK film industry, through the British Standards Institute, has recently introduced an environmental management system standard. Both of these programs are voluntary, and are described in more detail below.

\subsubsection{Green Seal}

The Environmental Media Association (EMA) was founded in 1989 to drive awareness of environmental issues through the actions and content of members of the entertainment community (EMA n.d. a)

In conjunction with Green Seal (a nonprofit environmental certification standard developer), the EMA has developed a program of recognition for film and television productions (EMA n.d. a). By achieving a set value in the selfassessment, a production may qualify for the certification. There is no mandatory verification process, but going through verification does award additional points in the evaluation process.

The voluntarily assessment form has become progressively more detailed. Initially, the form was eighteen questions long, where respondents scored themselves from one ("needs improvement") to five ("best") (Table 3). The assessment form offers an indicative array of the types of sustainability initiatives that are available to a production. 
Table 3

Environmental Media Association "Green Seal" Scorecard in 2007

1 Use certified renewable/sustainable building materials for set construction (not endangered rainforest hardwood sold as "meranti" or "lauan").

2 Use paints, sealants and lacquers that are low-emission (low VOC) and less toxic.

3 Lease hybrid and/or electric vehicles for the production whenever possible.

$4 \quad$ Request that traditional transport vehicles not idle.

$5 \quad$ Buy ultra low sulfur diesel (available at ARCO stations) for all production vehicles.

6 Use bio-diesel fuels for all auxiliary power generators.

7 Use non-toxic cleaning products and buy unbleached, high recycled content items for production offices (paper towels, plates, cups, office paper, pencils, t-shirts).

8 Reuse or donate unwanted production materials and supplies (sets, paints, props, office products, etc.)

9 Arrange for all set materials and office equipment to be recycled or donated. Coordinate with non-profits and local schools before production ends.

10 Recycle production office materials (paper, plastics, glass, cans, cardboard, wood, VHS, Digi Beta cams, DVDs, etc.).

11 Make sure food/beverage suppliers \& caterers provide reusable, recyclable and/or biodegradable serving products, instead of styrofoam and plastic.

12 Request that caterers provide food that is locally sourced and is organic or sustainable.

13 Ensure that recycling bins are located in convenient and easily accessible locations on set and in production offices.

14 Arrange for a local food bank to pick up leftover food at the end of each day.

15 Go paperless whenever possible utilizing electronic forms of communication. Only print scripts on demand.

16 Use tablet PCs or digital dailies; email revised scripts.

17 Brief the publicity department on the production's environmental commitment and have everyone involved speak about it when speaking to the press and on publicity tours.

18 Offset carbon emissions

Adapted from The Environmental Media Association [EMA] (n.d. d).

The current self-assessment form, still voluntary and conducted as a selfevaluation, has evolved into thirteen representing a much broader category of impacts and potential initiatives, as seen in Table 4.

Each section includes a set of weighted strategies against which a production evaluates themselves, with some strategies being mandatory (e.g., having an environmental policy in place). For example, a total of three points are available for using energy efficient lighting, and a production would self-evaluate their success on that strategy by scoring themselves to a maximum of three 
Table 4

Environmental Media Association "Green Seal" Scorecard in 2013

\begin{tabular}{cl}
\hline 1 & Mandatory \\
\hline 2 & Energy and Emissions \\
\hline 3 & Water Conservation and Management \\
\hline 4 & Waste Reduction and Management \\
\hline 5 & Transportation \\
\hline 6 & Catering and Craft Services \\
\hline 8 & Purchasing and Set Materials \\
\hline 9 & Wardrobe and Makeup \\
\hline 10 & Office Operations \\
\hline 11 & Education and Messaging \\
\hline 12 & Innovation \\
\hline 13 & Site Visit \\
\hline 14 & Aspirational Items (Bonus Points) \\
\hline Adapted from The Environmental Media Association [EMA]
\end{tabular}

(n.d. e).

points. Some strategies are pass/fail, for example: DVD includes a section highlighting green practices that were implemented, worth two points, and requiring $100 \%$ compliance (or a pass) to earn a full score. A score of 40 points out of a possible 145 is required for recognition.

Participation in the Green Seal award program has steadily increased. In 2004, five Green Seal Awards were conferred; in 2011, twenty two film and television productions were recognized (EMA n.d. c). Nominees and winners are feted at a gala event that is well attended by Hollywood personalities, which is a strong measure of the brand awareness of this organization.

\subsubsection{BS 8909 EM Specification}

The BS (or British Standard) 8909 offers a different approach. It is the first environmental management system specification developed exclusively for the film industry. It does not represent a performance certification in itself, as it does not contain objective measurement criteria; but like all management standards, it provides an operating and organizational framework from which to incrementally 
improve an organization's environmental performance (British Standards Institution [BSI] 2011).

Released in 2011, the standard was developed by the BSI in conjunction with industry experts in the United Kingdom. A set of guidance notes developed in conjunction with the standard notes that the development motives for the standard were to address sustainability within the industry, to keep the industry ahead of legislation, and to assist in creating a competitive advantage for the jurisdiction (BSI 2011). There was an explicit desire on behalf of the developers that the standard enables producers to include a claim in the film credits that reads in the vein of "this film was produced by [name of organization], which operates a sustainability management system that conforms to BS 8909" (BSI 2011, p. 4).

The standard is geared towards feature film productions, although it is acknowledged that it could be applied to a broader range of screen production, including television (BSI 2011). In the familiar plan-do-check-act format of a management system standard, BS 8909 works by requiring a company to establish sustainability goals and objectives, and then evaluating the final results against those initial objectives (BSI 2011).

The plan-do-check-act system (Thompson 2002) of continual improvement in a management system standard is seemingly at odds with the constraints of a project-based organization. While nothing would preclude a film PBO from following the standard, there is real question as to whether sufficient time would be allowed for any meaningful improvement in environmental performance. If dissolution of the enterprise occurs within months or even weeks, what progress could be made, and how might it be tracked? In addition, the same questions discussed regarding knowledge transfer are again applicable: is it possible to raise the starting point of each successive production, to align with developed competencies in previous ones? In other words, can the application of the standard help to continually raise environmental performance industry wide, even 
if applied to discrete productions?

\subsection{Sustainable Construction}

The next goal of the literature review is to explore sustainable construction, to determine what similarities may exist to the target industry of film production. Sustainable construction has been defined as (Van Bueren and Priemus 2002, p75):

the design, development, construction, and management of real estate such that the negative environmental effects of the construction, restructuring, and management of the built environment are reduced as far as possible.

Learning experiences, barriers overcome, and development paths all may offer some constructive insight into the film industry's efforts. The result of this portion of the review is to offer methodological support for the use of the projectbased analysis framework, the comparison industry choice, and to frame the interview results and discussion within the established literature.

\subsubsection{Industry Drivers}

The construction industry has long been under pressure from government agencies, citizens, environmental groups, and private owners to manage the impacts from new construction and ongoing building operations (Vanegas and Pearce 2000). The construction industry is one of the major contributors to the depletion of natural resources, and a major source of emissions, toxic waste, deforestation and global warming (Augenbroe and Pearce 1998). Vanegas and Pearce (2000) identify the drivers for this attention as stemming from the construction industry's significant presence and contribution to the following:

- Natural resource depletion and degradation;

- Waste generation and accumulation;

- Negative impacts to ecosystems, including human health. 
Augenbroe and Pearce (1998) are slightly more specific when identifying the impacts associated with urban sprawl that is creating drivers towards sustainable construction:

- Increasing traffic congestion and commute times;

- Inefficient energy consumption and greater reliance on foreign oil;

- Loss of open space and habitat;

- Inequitable distribution of economic resources;

- Loss of sense of community.

The result of a Swedish construction industry survey (Thuvander et al. 2011) determines that the principal drivers for environmental management activities are the long term benefits to the business. These benefits include positive effects on (with percentage of respondents that indicated the benefit):

- Company image (85\%)

- Pleased personnel (77\%)

- Pleased management (78\%)

- Long-term profit (64\%)

- Pleased owners/shareholders (63\%)

- Product image (61\%)

- Competitive advantage (58\%)

- Cost savings (52\%)

- Sales (48\%)

- Recruitment (47\%)

- Market advantages (44\%)

- Market shares (36\%)

- Productivity (27\%)

- Short-term profit (27\%)

- Improved insurance terms (14\%)

- Improved financing terms (12\%)

Thuvander et al. (2011) note that environmental management in the Swedish construction industry is still very much in a self-regulation phase, and that the 
lack of business opportunities from green business - whether this is short term profit, or the development of new technology - are preventing market forces from becoming the dominant environmental driver in the industry.

Shen and Tam (2002) produce a relative list of benefits, presented in decreasing significance to the construction company:

- Contribution to environmental protection;

- Reduction of environmental risks - polluted air, land and water;

- Improving corporate image in environmental performance;

- Contribution to the improvement of public environmental standards;

- Reduction of environmental complaints;

- Reduction of environment-related sickness and injuries;

- Increasing overall business competitiveness;

- Improving staff work environment, thus increasing their morale;

- Cost saving due to the reduction of fines associated with convictions.

Shen and Tam's (2002) list illustrates that the most immediate benefit for environmental management in the construction industry is the reduction in the level of impacts to the environment. Cost savings, competitiveness, and staff morale are among the least significant benefits to the construction company.

Manoliadis et al. (2006) conducted a Delphi study to produce a ranking of the most important sustainable construction drivers in the Greek construction industry:

- Energy conservation,

- Resource conservation,

- Land use regulations and urban planning policies,

- Waste reduction measures,

- Environmentally friendly energy technologies,

- Education and training,

- Adoption of incentive programs,

- Re-engineering the design process, 
- Indoor environmental quality,

- Adoption of performance based standards,

- Better ways to measure and account for costs,

- New kinds of partnerships and project stakeholders,

- Product innovation and/or certification,

- Proactive role of materials manufacturers, and

- Recognition of commercial buildings as productivity assets.

The reduction of environmental impacts (through energy consumption, waste generation, and resource consumption) is again the most important driver for sustainable construction, and aligns with the study by Shen and Tam (2002). Lower on the list is the need for a performance standard, and improved cost accounting measures. The benefit to construction companies in the form of positive corporate image or competitiveness was a moderate driver when identified, but is notably absent (along with any other firm specific benefit) from the Manoliadis et al. (2006) study.

Environmental performance standards figure strongly in green building. The Leadership in Energy and Environmental Design (LEED) designation was developed to evaluate environmental construction for commercial building against a defined standard ("LEED Rating System" 2011). The LEED certification standard uses an absolute scoring system, compiling points in a number of categories which include: location, water efficiency, energy and atmosphere, materials and resources, indoor environmental quality, and innovation and design process (Fuerst and McAllister 2011). There are four tiers in the system, platinum, gold, silver, and certified (Fuerst and McAllister 2011). The Energy Star standard is typically used for existing buildings (as opposed to new construction), and is a measure of the building's energy performance (Fuerst and McAllister 2011), where the LEED certification is a more holistic approach (Demirsi and McDonald 2011). From an industry driver perspective, a green designation can reduce operating costs and improve tenant satisfaction, but 
require an initial capital investment in areas such as design, material and appliance selection (Demirsi and McDonald 2011).

The construction industry drivers identified in the literature range from broad macro concerns (natural resource depletion) to micro, firm specific, issues (recruitment and stakeholder relations). Studies that rank these drivers agree that the most critical driver is the need to reduce environmental impacts, while competitiveness and cost savings potential are among the least important of those drivers.

\subsubsection{Industry Barriers}

Van Bueren and Priemus (2002) argue that sustainable construction has failed to materialize in the Netherlands, and identify the following barriers:

- A gap between location development and building project development: attention may not be paid to the environmental opportunities that are available from smart infrastructure planning decisions (in transportation, water, energy, and waste, for example), and ensuring that developers are aware of those opportunities. However, this gap can also manifest as a lack of coordination between these agencies, in that the required infrastructure needs to be available in the first place.

- A gap between construction and management: is the gap that exists between the goals of the project owner at each phase of development. The developer may be more concerned with producing a building that meets code, and the final unit owner with making environmental decisions that have not been adequately prepared.

- A gap between construction and use: the responsibility of the user to adapt their behaviour to the sustainability potential that has been constructed. A simple example is ensuring that the owner uses heating and cooling equipment as designed.

- The asymmetric distribution of costs and benefits: cost burdens and financial incentives may not rest with the same, nor the most appropriate, 
entities. Cost uncertainty also prevents the full burden of those costs from being passed on to the user. The absence of user influence on the product is such that the developer concentrates on investment decisions using only cost as a factor (the end benefit to the consumer does not factor in to the evaluation).

These barriers all illustrate an important consideration in the construction industry: there exist multiple stakeholders who are frequently involved at different stages of the project. Financial incentives and cost burdens can be realized with different entities, and stakeholder interests evolve or even begin at differing levels of sustainability commitment. There is a systematic barrier present which involves the need to align interests across the various system boundaries and changing actors.

Thuvander et al. (2011) provide a list of additional barriers to environmental management identified in the construction industry, further classified by whether they originate externally or internally in the organization, as found in Table 5. Thuvander et al.'s (2011) study revealed that the construction industry respondents frequently identified the barriers of lack of competitive advantage, lack of demand for green products, and cost as being high or very high in their influence on environmental activities.

Shen and Tam (2002) produce a relative ranking of the barriers to environmental management:

- Increase in management and operation costs,

- Lack of trained staff and expertise,

- Lack of sub-contractor co-operation,

- Lack of client support,

- Time-consuming for improving environmental performance,

- Lack of supplier co-operation,

- Difficult co-ordination of environmental performance among multi-tier subcontractors, 
Table 5

Construction industry barriers to environmental management

\begin{tabular}{ll}
\hline External & No demand for green products / services \\
\hline & Lack of willingness to cooperate from customer \\
\hline & Lack of willingness to cooperate from suppliers \\
\hline No competitive advantages \\
\hline No technical solutions available \\
\hline No regulatory incentives \\
\hline Lack of relevant information \\
\hline Lack of clear regulations \\
\hline Lack of reliable information \\
\hline Lack of willingness to cooperate within sector \\
\hline No regulations \\
\hline Cultural heritage demands \\
\hline Lack of educated personnel \\
\hline Lack of knowledge on available tools \\
\hline Too costly \\
\hline Lack of financial resources \\
\hline Communication difficulties \\
\hline Insufficient organizational structure \\
\hline Lack of management support \\
\hline Counteracting organizational structure \\
\hline Organizational difficulties
\end{tabular}

Adapted from Thuvander et al. (2011).

- Lack of working staff support,

- Increase in documentation workload,

- Lack of technological support within organization,

- Lack of tailor-made training on environmental management,

- Lack of government legal enforcement, and

- Change of existing practice of company structure and policy.

It is not unexpected to see that cost increases are the most significant barrier to environmental management in this construction industry survey. The lack of cooperation between the construction entity and the supplier, client, and subcontractors presents a picture of the construction entity as an island, with very little ability to influence the environmental activities of its key operating stakeholders, and was also identified by Thuvander et al. (2011). It is interesting 
to note that respondents to this survey did not feel that changing internal structures to accommodate new environmental practices or policies would be a relatively significant barrier, although this was cited as an internal barrier by Thuvander et al. (2011).

Twelve barriers to sustainable construction in England were identified in a study by Williams and Dair (2007), in decreasing order of citation:

- Sustainability measure not considered by stakeholders;

- Sustainability measure was not required by client (end user);

- Stakeholder had no power to enforce or require sustainability measure;

- One sustainability measure was foregone in order to achieve another;

- Sustainability measure was restricted by regulators;

- Sustainability measure cost too much;

- Site conditions mitigated against the use of a sustainability measure;

- Inadequate, untested or unreliable sustainability materials, products, or systems (including long term management problems);

- Sustainability measure was not available;

- An unsuitable measure was allowed by the regulator (no driver for sustainable alternative to be used);

- Stakeholder was not included in the development process;

- Stakeholder lacked information, awareness or expertise to achieve sustainability measure.

The study highlights the gap that exists in sustainability knowledge and skills, at both the planning and execution levels (Williams and Dair 2007). The study also identifies a lack of demand from the end user for a sustainably built environment, and in the absence of regulatory requirements that require otherwise, there is little incentive to change existing practices (Williams and Dair 2007). Like the study by Van Bueren and Priemus (2002), this study reinforces the barriers that can manifest through the interactions of a revolving set of 
stakeholders, and the ultimate need for alignment on the sustainability front from the outset of a project's inception.

\subsection{Summary}

A review of the literature for project-based organizations yields a working definition, and supports the classification of both the film and construction industries as members of that class. Inherent structural barriers are identified in this type of organization, including challenges relating to the accumulation of core competencies through innovation and knowledge transfer. It is expected that the development of a core competency of environmental management on a film production would experience some form of these challenges. The literature also reveals the strong role that networks of relationships play in the PBO, or the "social context", as a means of permanence beyond the limited life span of the PBO. The "organizational context" describes a form of permanence through the organizational entities that persevere after the demise of the temporary organization. The motivations for ecological responsiveness in permanent organizations are identified, and allow an opportunity to align against those of the PBO.

The structure of the motion picture industry is briefly reviewed, to situate the research against the broader industry context. The various stages of film production are explained, and further details provided on the stage of interest to this research, the Production stage.

A review of the literature on environmental management in the film industry reveals recent efforts at identifying impacts and quantifying emissions from that sector, and confirms that the industry is a significant polluter. The environmental tools available to the industry are reviewed, with respect to certification options and a management system standard. Sustainable construction drivers and barriers are also revealed through the literature, which allow a basis for comparison against the film industry. 


\subsection{METHODOLOGY}

This thesis is a qualitative research study, which uses the techniques of a literature review and key informant interviews as the principal means of data collection. One advantage of a qualitative study is that it produces data with "depth and detail to create understanding of phenomena" (Bowen 2005, p205).

A quantitative approach may have produced interesting results in its own right; however, there are two main reasons that this approach was not used. The first reason is that the sample size available within the industry under study is relatively small. Qualitative approaches "tend to work with a relatively small number of cases" (Silverman 2005, p14), and perhaps avoid the risk of a quantitative approach being statistically skewed as a result of that sample size. The second reason is that the quantitative approach would not necessarily yield the context for a certain response. While the researcher is interested in what strategies these respondents employ, and what barriers they encounter; it is also why they were chosen, and why a barrier arose in one production, and not another. Denzin and Lincoln (2005) argue that capturing the subjects' perspective is better achieved through a qualitative method than a quantitative one.

Finally, the use of a qualitative method in this study allows the researcher to be responsive to the cues being provided by the participants, to manage the approach to an issue so that it is least sensitive to the subject. A qualitative approach is superior to the quantitative approach in this respect, as the researcher is able to be flexible and make decisions based on the feedback being received (Padgett 2008).

\subsection{Key Informant Interviews}

Interviews were conducted between September 2010 and May 2012. Interviews were in person whenever possible, and conducted over the phone when required by distance or schedule. 
The scope of the interview was known by the participant in advance; however, the exact order and specific content of questions was informed by the topics already discussed, and overall flow of the interview. This semi-structured approach with open ended questions was informed and described by Seidman (1991). Kvale (1996) also supports this style of approach, which holds that the same path cannot necessarily be followed for each participant.

Key informants were selected using the qualitative sampling technique of purposeful sampling (Patton 1990). The criteria for being selected to participate in the study focused on those individuals who had familiarity with both film production and environmental management, and ideally, those fields together. The following is the specific types of key informant sought to respond to the research:

- studio executives, whose responsibility include production sustainability; identified through networking, website review, news articles;

- environmental consultants, who design programs for film productions or have published a guide on the behalf of a film jurisdiction;

- film production personnel, who are actively involved with sustainability within productions.

Film production is a relatively specialized field, and for this reason environmental consultants without that specific experience were not believed to be suitable candidates for the study. Film production personnel that had no direct experience with environmental management practices on a production were similarly excluded.

An initial set of twenty individuals were identified through the literature and web searches as viable key participants, based on the above criteria, and within North America. An additional six people were identified through snowball sampling. A total of twelve interviews were ultimately conducted, lasting between thirty and sixty minutes each. 
The overall sample size was limited by the specialization of the topic. While every effort was made to identify appropriate subjects, some may have been overlooked. The end result is that while this field is growing, and the potential pool of respondents with this niche expertise is expanding with time, the sample size at the time of this study was still relatively small. Davenport (2006) echoed this limitation in his study of the project-based nature of UK film companies, managing an interview sample size of just nine from a pool of sixty-six potential companies. With this consideration, conducting twelve interviews for a $46 \%$ response rate is relatively successful.

While a larger sample would have been desirable, and a handful of respondents did not respond to interview requests or otherwise declined, there was sufficient evidence of convergence and literature precedents that make this a satisfying number of respondents. Each respondent expressed individual observations, but there was a sufficient number of key informants such that responses to certain questions were similar in nature, providing some confidence through this convergence in the quality of the data being collected. As a further measure of support, Guest et al. (2006) indicate that saturation can be achieved in some qualitative studies within twelve interviews. There was also an indication that a saturation point had likely been reached, given that potential participants being suggested by key informants in the later stages of the interview process had already been approached. Respondents were successfully obtained from four distinct areas of the industry to maximize the collection of divergent data, with the occupational profiles found in Table 6.

Subjects were recruited using cold call emails, and references from other key informants. As indicated, a total of twelve individuals agreed to participate; the balance of informants chose not to reply to the solicitation. ${ }^{1}$ Key informants were offered confidentiality in both name and organization. Many subjects were located in California, and interviews were conducted on location in person when

\footnotetext{
${ }^{1}$ Based on the interviews, key informants believed those who did not reply were reluctant to contribute due to privacy concerns for themselves and/or their organizations. However, this cannot be independently confirmed.
} 
Table 6

Occupational profiles of interview respondents

\begin{tabular}{clcc}
\hline$\#$ & Position & $\begin{array}{c}\text { Type of Firm / } \\
\text { Related Experience }\end{array}$ & $\begin{array}{c}\text { Interviewee } \\
\text { Location }\end{array}$ \\
\hline 1 & Environmental Consultant & $\begin{array}{c}\text { Sustainable Production } \\
\text { Services }\end{array}$ & Toronto \\
\hline 2 & Production Manager & Production Company & Toronto \\
\hline 3 & Sustainability Manager & Major Studio & Los Angeles \\
\hline 4 & Production Executive & Major Studio Subsidiary & Los Angeles \\
\hline 5 & Sustainability Manager & Major Studio & Los Angeles \\
\hline 6 & Production Executive & Major Studio & Los Angeles \\
\hline 7 & Manager & Government / Film Industry & Vancouver \\
\hline 8 & Executive & Major Studio & Los Angeles \\
\hline 9 & Environmental Consultant & Sustainable Production & Los Angeles \\
& & Services & \\
\hline 10 & Technical Union Member & Production Company & Toronto \\
\hline 11 & Producer & Production Company & Los Angeles \\
\hline 12 & Producer & Production Company & Los Angeles \\
\hline
\end{tabular}

feasible, and via telephone otherwise. A consideration that should be noted is the possibility of a selection bias, as the respondents' interest and dedication to the field of environmental management and its application may frame some of their responses. The territorial scope of the film productions under consideration is heavily weighted to North America, with some anecdotal references from the subjects to other territories. Some studio representatives would bring an international perspective to sustainable production issues as part of their day to day responsibilities, but this would represent a very minor portion of the content of their responses. It would be appropriate to categorize responses as being generally for the North American production experience, except where otherwise noted.

Upon agreeing to the interview request, respondents were provided with an information package to familiarize themselves with the purpose of the research. The documents provided included:

- a Research Summary, which provided a brief background on the 
study, including its aims;

- a Consent Form, to confirm awareness of participation in research that has been submitted to and approved by the Ryerson Ethics Board;

- an Interview Template to provide an indication of the topics that would be discussed during the actual interview (see Appendix A).

The interviews were recorded with permission, and the recording was transcribed at a thematic level, following Kvale's (1996) approach to meaning condensation. In conjunction with notes taken during the interview, responses and statements were condensed into themes, which generally corresponded to the topics under the scope of the study. For example, mentions of drivers and barriers were synthesized into a comprehensive list. The methodology did not allow for a ranking of the discovered drivers and barriers in a relative scale of importance. A higher frequency of identification is not necessarily an indication that the driver identified is of greater consequence than another that was identified fewer times. Given the overall theme that productions are unique, relative importance may in fact just be on a case by case basis. However, it would have been informative to have the ability to focus on a single case study to obtain a perceived ranking of importance for these driver and barriers. This does make it available as a topic for future research.

The individual thematic groupings were then combined to allow for further analysis. For example, all references to budgetary concerns on a film production and its impact on environmental management were grouped and analyzed.

Patterns were noted at this higher level, including where there was agreement or divergence between respondents.

\subsection{SWOT Analysis}

Identified drivers and barriers can also be classified further through a typology analysis. The organizational structure of the production company (the PBO) offers a method to interpret the data by determining whether the impetus comes from inside or outside the PBO, an approach also used by Thuvander et al. 
(2011) in evaluating drivers and barriers to environmental management in the construction industry. The results in that study were informative, and as a result, the procedure was utilized in this study as well. Given the focus of this research on the PBO, a natural system boundary was available, and the approach seemed appropriate.

For this research, the system boundary is defined as the PBO itself. Drivers and barriers are then categorized as being internal (originating or acting from within the $\mathrm{PBO}$ ) or external (originating or acting from outside the PBO). Figure 2 , which shows the PBO (in red), is certainly not exhaustive in defining external actors (in blue), but should clarify the intent of the definition.

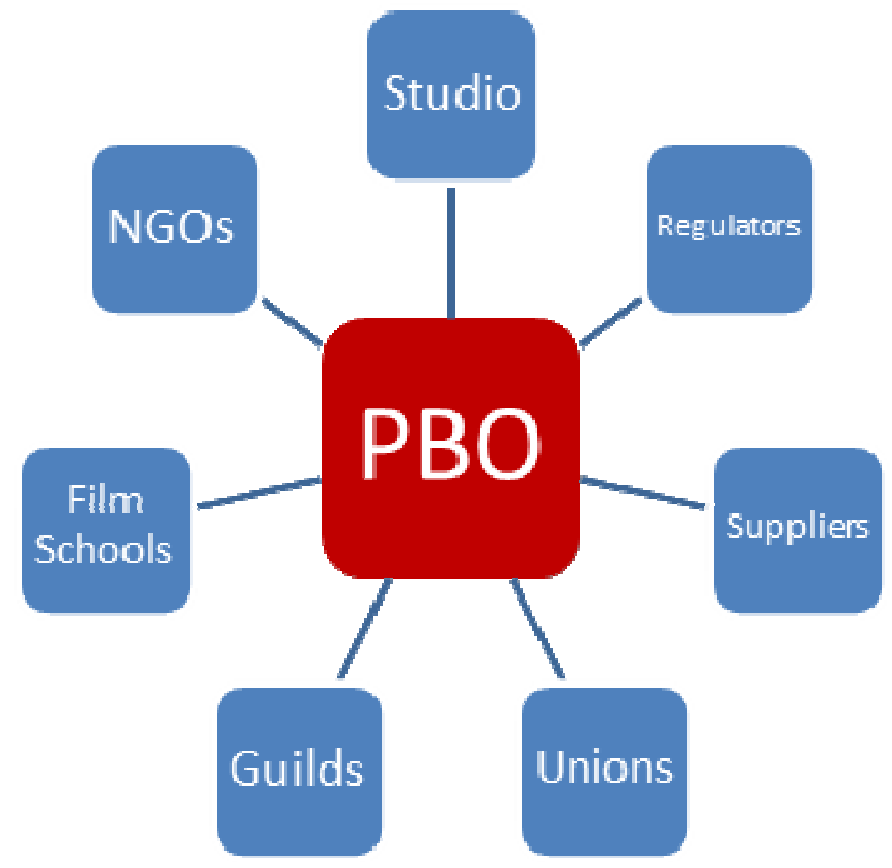

Figure 2. Project-based organization as SWOT system boundary.

The Strengths Weaknesses Opportunities Threats (SWOT) methodology was then utilized, and permitted a final classification of the drivers and barriers according to the PBO system boundary. Under this analysis, a driver originating from within the PBO is considered a strength of the organization. A barrier that originates from within the PBO would be classified as a weakness.

A driver that originates outside the PBO is considered an opportunity. A 
policy directive from the studio, for example, and would be classified as an opportunity. A threat would be a barrier that originates from an external source. Opportunities and threats are not characteristics of the PBO itself, and exist externally to it. The PBO's ability to influence or react to the opportunity or threat is also an important question.

How the SWOT methodology was used to classify the results of the typology analysis is summarized in Table 7.

Table 7

SWOT analysis of drivers and barriers

\begin{tabular}{|l|l|l|}
\hline & Drivers & Barriers \\
\hline Internal Origin & Strengths & Weaknesses \\
\hline External Origin & Opportunities & Threats \\
\hline
\end{tabular}

The scope of this analysis is limited to the ability of the PBO to implement an environmental management program only, and does not apply to any other area of business acumen.

Following the example set in Thuvander et al. (2011), and to enable a comparison between the two industries, the construction industry drivers and barriers identified through the literature were put through the same SWOT analysis. Specifically, drivers and barriers that originated from within the construction PBO itself were classified as strengths and weaknesses respectively; drivers and barriers that originated from sources external to the PBO were classified as opportunities and threats. The complete construction industry SWOT analysis is presented in Appendix B.

Finally, Figure 2 provides an opportunity to define the stakeholders in an environmental management program in the film industry. A stakeholder is 
defined as an entity that is involved or affected by the PBO's actions with respect to its environmental management efforts. Figure 2 identifies a few of the stakeholders, including the studio, regulators, non-governmental organizations, and suppliers. 


\subsection{RESULTS}

One of the primary goals of the interviews was to identify the drivers and barriers that are specific to environmental management in the film industry, and then to classify those by an organizational structure typology, and finally to present the results in a SWOT analysis.

Respondents were prompted specifically to identify drivers and barriers, which yielded the initial thematic groupings. There were instances where drivers and barriers were revealed at other times (not under specific questioning) during the interviews, but the classification of those statements as either a driver or barrier was relatively straight forward given the context of the discussion.

The organizational typology results (the classification of the drivers and barriers as internal or external to the PBO) was achieved by identifying the source of the driver or barrier. In areas that proved challenging to identify a single source (or the line was blurred between internal and external), the dominant source was used.

The results of the SWOT analysis are summarized in Table 8. It is important to note that these strengths, weaknesses, opportunities and threats are not necessarily present in every PBO in the film industry. Interview respondents have simply noted the existence of these issues, typically during the course of implementing an environmental management program on a specific (or on multiple) projects. 
Table 8

Results of SWOT analysis

\begin{tabular}{|c|c|c|c|}
\hline & $\begin{array}{c}\text { Number of } \\
\text { Respondents } \\
\text { Who Identified }\end{array}$ & $\begin{array}{c}\text { Internal / } \\
\text { External }\end{array}$ & SWOT \\
\hline \multicolumn{4}{|l|}{ Drivers } \\
\hline Social Conscience & 7 & Internal & Strength \\
\hline Champions & 4 & Internal & Strength \\
\hline Talent Incentive & 3 & Internal & Strength \\
\hline Budget Availability & 3 & Internal & Strength \\
\hline Reduced Costs & 3 & Internal & Strength \\
\hline $\begin{array}{l}\text { Quantification / } \\
\text { Measurement }\end{array}$ & 2 & Internal & Strength \\
\hline Early Adopter & 1 & Internal & Strength \\
\hline Certification & 6 & $\overline{\text { External }}$ & Opportunity \\
\hline Policy or Mandate & 5 & External & Opportunity \\
\hline $\begin{array}{l}\text { Non-Government } \\
\text { Organizations }\end{array}$ & 2 & External & Opportunity \\
\hline Consumer Demand & 1 & External & Opportunity \\
\hline $\begin{array}{l}\text { Unions / Guilds / Film } \\
\text { Schools }\end{array}$ & 1 & External & Opportunity \\
\hline Regulation & 1 & External & Opportunity \\
\hline \multicolumn{4}{|l|}{ Barriers } \\
\hline Crew Cooperation & 7 & Internal & Weakness \\
\hline Nature of Business & 5 & Internal & Weakness \\
\hline Knowledge Transfer & 3 & Internal & Weakness \\
\hline Delay in Implementation & 3 & Internal & Weakness \\
\hline Behaviour Modification & 2 & Internal & Weakness \\
\hline $\begin{array}{l}\text { Quantification / } \\
\text { Measurement }\end{array}$ & 2 & Internal & Weakness \\
\hline Location Department Buy-In & 1 & Internal & Weakness \\
\hline Budget & 8 & External & Threat \\
\hline $\begin{array}{l}\text { Service / Product } \\
\text { Availability }\end{array}$ & 8 & External & Threat \\
\hline Certification & 5 & External & Threat \\
\hline No Competitive Advantage & 3 & External & Threat \\
\hline No Environmental Line Item & 2 & External & Threat \\
\hline Brand Awareness & 2 & External & Threat \\
\hline Unions / Guilds & 1 & External & Threat \\
\hline Government Agencies & 1 & External & Threat \\
\hline Studio Issues & 1 & External & Threat \\
\hline
\end{tabular}




\subsection{Strengths}

\section{Social Conscience}

The strength identified by the greatest number of respondents was the idea of a "social conscience", succinctly described by one subject as "the right thing to do" (Subject 4). To highlight the relative importance of this organizational strength, another respondent indicated that at this stage of environmental program sophistication (from an industry perspective), doing the right thing is the only real motivation for an environmental program (Subject 2). The implication of this statement is that the relative importance of any of the other driver under discussion - consumer demand, corporate policy, or cost advantages, for example - is relatively minor.

However, from a methodological perspective, it is important to note that this study does not allow for the identified strengths and opportunities from the interviews to be given a hierarchal structure according to relative importance. A frequency analysis, like the one structured above, simply reports the number of times that the driver was identified. A higher number of mentions from these respondents may indicate that a driver is more commonly present, more generally salient, or easier to recall or identify; but, it does not necessarily mean that it is more important than one with fewer mentions. This was not specifically addressed initially in the methodology, and should be a target of refinement for future study.

The fact that some people are bringing their social conscience to work is evident, as more than one respondent noted that, referring to environmental management strategies, they "do it in my own life", and that they cannot compartmentalize work and home life (Subject 12). Environmental management is not something you "can turn on and turn off" (Subject 12). The fact that personal conscience is an important strength in implementing an environmental strategy on a film production indicates that these early adopters are environmentally aware on a personal level. The desire to implement a social 
more in a work environment is a common characteristic among many of these respondents, and it may be fair to say that the initial momentum behind the environmental effort was the result of the actions of a strong willed minority. However, if one is to consider the long term potential of the sustainability initiative, there may be a real concern if the major strength of the initiative remains only the goodwill of the industry's crew members. Not all employees will be decision makers, which would limit the ability to implement these types of strategies. The other strengths and opportunities identified in the interviews do suggest that this is not the case, and that other motivations are arising.

While reducing impacts on the environment is absolutely the reason behind environmental management efforts (Subject 6), just one respondent, Subject 8 , tied the social conscience driver to the sustainability of the industry as a whole. This may imply is that industry sustainability as a concept is still not yet well entrenched, even among the industry's "experts", a finding that would agree with Corbett and Turco (2006). This would further suggest that not much progress has been made on the front of raising the overall profile of environmental management within the industry itself.

\section{Champions}

Champions are crew members who help to drive environmental management efforts, and otherwise facilitate the implementation and operation of an environmental program. Without exception, the respondents who noted this strength (Subjects 5, 9, 10, and 11) indicated that the champion needs to be a senior executive in the production (in film language, someone "above the line"), or one who can provide resources, policy support and approvals as needed. Thuvander (2011) found the same to be true in the construction industry, in that the influence of the environmental program was connected to the formal position of the responsible manager. All four of the respondents indicated a producer's buy-in is required; and three of four indicated that the director's buy-in is needed. The respondents believe that it may be enough to have just one of these senior executives on board, but that the key, as Subject 9 noted, is that "once the 
director is on board, you can defer questions of compliance right to the top, where people are reluctant to go." The production manager is also a key enabler, as is the production coordinator, positions that were both identified once (Subject 5). Corporate politics does play a factor, as one respondent noted an important requirement is that you need "access" to that champion. Often, "these players are significantly insulated", and factors of perceived power, status, and ego can also make it challenging even "just to ask the right questions" (Subject 9).

One manifestation of the on-set champion is the environmental steward, a dedicated resource to implementing, promoting, and ensuring compliance with an environmental management program. A steward could be the recipient of specialized training, but likely builds her competencies through previous experience with environmental work on another production (Subject 8). As a full time crew member, the steward brings an inside knowledge of film production processes (and a certain on-set sophistication) that an external resource may not initially possess.

An interesting twist on the internal champion strength is the role that an outside environmental consultant can play. Technically an outsider, many productions will bring in an outside consultant to implement an environmental program (Subject 1, 9). The consultant can interact with an executive committee comprised of the senior (or "key") department members on the production, or just a single resource. With sufficient effort and presence, the external consultant can assume the role as a de facto internal champion, gaining familiarity with crew members and a form of acceptance and authority (Subject 10).

Finally, there is the role of the studios. Most, if not all, of the major studios now have sustainability or environmental departments, whose responsibilities include disseminating strategies and policies to their respective productions (Subjects 3,5 ). It is important to note that while most production companies are "one-off" entities (Subject 4), or PBOs, they are formed by parent companies (the studios) that frequently have an ongoing commitment to certain environmental 
practices. Studio employees who manage these departments were targeted and interviewed for this study. These managers also have the ability to act as a champion on each production on their respective studio's slate. This aspect of the champion strength is more accurately considered an opportunity (as the studio is external to the PBO).

\section{Talent Incentive}

"Talent Incentive" was identified by three respondents (Subjects 5, 6, and 7), and represents the desire of a key cast member to have an environmental program in place on the production. This strength can be "an immense help" (Subject 6) to getting a program implemented. Subject 7 stated that in the "majority of [their] experience, a formal program prepared by the production has been the result of a talent request."

While identified separately, there is an argument to be made that the talent incentive is simply a variation of the champion strength previously identified. Actors are a paid member of the production just like any other crew member, and their interest in implementing an environmental management program serves to present them as a champion of the cause. In combination, the talent incentive and champion strengths would be the second most frequent strength cited by respondents, with six unique references.

The reason they have been separated for analysis is that the while an actor is also a crew member, key talent wields a form of leverage that a typical champion from the crew does not. Given that an actor typically has a significant public profile, they have an ability to influence operations on a scale that is matched by only a handful of others involved with the production. For those reasons, their role in driving an environmental management program can be impactful yet limited to simply requesting the production to put such a program in place, while not necessarily choosing to act as the on-set champion or everyday resource. 
Despite being identified as a strength by three respondents, two respondents believed talent had little awareness of, or ability to impact, an environmental program (Subjects 2 and 9). Subject 2 believes the talent on their production was "likely unaware of efforts" around a green program that had been implemented, and expressed curiosity on what their opinion of such an effort would be. Subject 9 also believes that a green initiative cannot be seen - and has never been used - as a "talent attractor".

While seemingly at odds (some identifying a talent incentive as a strength, and others specifically identifying that it is not), the intent of each does not quite overlap. While a cast member can be a highly motivating force for the implementation of a program in some cases, the ignorance of the existence of a program does not necessarily mean they are an unavailable resource; they may simply be an untapped one. Similarly, the fact that a cast member may not choose to do a movie with an environmental program in place as a prime factor for consideration does not necessarily imply that they could not (or would not) act as a champion once signed. Talent clearly represents a strength of the PBO that may not be seen as a critical resource.

\section{Budget Availability}

"Budget availability" was also identified by three respondents, and is defined as the presence of a line item within the budget that is dedicated for environmental items. Subject 9 stated:

[It] was absolutely necessary to have a budget line item for environment. There is no way to overcome budget arguments without a line item to direct costs.

There is also the desire to have the PBO see the item in their budget to bring additional attention and light to the studio initiative. Subject 11 noted that one studio now includes a significant environmental item in their budget which can be used for any related purpose (e.g., wages, products).

The practical benefit of a line item of this kind is due to the departmentalized nature of film production. Budgets are allocated to each department, but the 
financial cost of a mandated or voluntary environmental measure may be poorly distributed across those departments. The rental premium to rent a hybrid electric vehicle, for example, would impact the Transportation department's budget alone. One possible solution to this inequitable cost burden is to have all environmental costs come from the same centralized budget line item, so that no single department is overly taxed (Subject 9). Subject 11 noted that this enables productions to budget for an environmental program specifically.

There is another direct benefit of having an allocated budget for environmental efforts, and that is the ability to hire an "environmental steward" (Subject 9). While Subject 11 indicated that tasks associated with an environmental program could simply be added to the duties of another staff member, the availability of a budget line item may enable an employee to take on the role full time over the course of a production. Subject 6 noted that a personable environmental steward can go a long way to helping persuade that proportion of the crew that is inevitably pre-disposed to opposing the goals of an environmental program. Lack of budget means a dedicated environmental steward is rarely available on a production, but there may be an opportunity to bundle duties into the responsibilities of an already budgeted crew member (i.e., a cast or executive assistant, or a production assistant).

The motivation for having an environmental steward ties back into the general discussion on the overall desire for having an environmental program in place. A talent request, for example, may be sufficient to have the production allocate funding for such a position (Subject 8). The reward to the production can be a robust environmental program that includes laborious emissions tracking and reporting, and report preparation and presentation (Subject 8).

\section{Reduced Costs}

The opportunity to reduce costs through sustainability measures is available, believes Subject 1 . Subject 2 also noted that cost savings are a real possibility, citing the savings realized from implementing a no idling program, and from 
delegating the responsibility for shutting off lights and heat or air conditioning at the end of the production day. However, Subject 2 believes the increased cost in other areas of the program likely mean it is a revenue neutral effort. There is also the risk that an environmental program will be perceived by the crew as simply a cost savings measure in disguise, according to Subject 2 , but that developing a business case for implementing these initiatives is often a requirement to obtain necessary approvals. Subject 3 also believed that whatever cost savings may be realized through using rechargeable batteries, for example, is likely offset by expenditures in other areas.

Three respondents (Subjects 4, 5 and 6) believe there is no financial incentive to a green program. This may partly be due to the challenge of measuring any cost savings associated with a program, as Subject 6 stated, we "can't prove that we are saving a lot of money, but we can prove that we are preventing greenhouse gas emissions."

\section{Quantification and Measurement}

Two respondents felt that a strength existed from the need to quantify the environmental impacts associated with film production, as what gets measured gets managed. In Subject 3's experience, the collection of these data is going to allow a baseline to be developed. For example, she "learned that the largest component of greenhouse gas emissions on a film production comes from the ground transportation component" (the trucks, passenger cars, and cargo vans associated with a production), which further allowed that production to target this area for reduction. Subject 6 noted that there is some corporate pressure to be able to measure and report emissions specifically, and ultimately to comply with a larger corporate environmental program.

\section{Early Adopter}

Subject 4 noted that these areas will "ultimately get regulated", and that a strength exists for those productions that can develop this environmental capacity. However, two respondents (Subjects 1 and 5) believed that being an 
early adopter provided no advantage. Subject 1 noted that it is true for any industry that there is value in being a first adopter, and overall development is difficult without a "someone leading the way"; however, she did not believe that there was any driving force or advantage to be gained from being a leader on this issue. Subject 5 noted that this phase of the industry's efforts "may have already passed". It may have been an important advantage in the beginning, but there is greater studio cooperation being seen, and there is no desire to compete on this front at that level (Subject 5). This cooperation is seen through an environmental committee, on which the heads of the sustainability departments from some of the major studios sit (Subjects 3, 5, 8). The specific procedures and goals of this committee were not revealed during the interviews, despite questioning, other than to confirm its existence. A carbon tracking solution (an Excel spreadsheet) was developed via this committee, standardizing some of the elements which are reported and quantified, with the ultimate goal of having a database that may allow future reduction targets to be set (Subject 5). Subject 5 also noted that with employees being able to freely move between studios, early pioneering efforts are often quickly adopted by competitors.

\subsection{Opportunities}

\section{Certification}

The most frequently identified opportunity was that presented by a certification option. Six respondents felt that environmental certification could ultimately drive performance. Subject 5 noted that her organization had some interest in a certification, but that the question is a "tough one", and still needs development. Subject 2 noted that some form of "eco-label" would raise visibility among consumers. Two respondents discussed the need for an external tax credit that offers financial incentives for a production that implements an environmental program, or achieves a yet to be defined environmental certification (Subject 1, Subject 3).

Subject 7 indicated that it would be good to have a standard that recognizes achievement. The worry is that there is a need to have a single standard, rather 
than a handful of regional standards of differing and confusing value. The other risk, is that the regional certification can be politicized and used for leverage in securing business. Subject 8 agreed that such a standard "would be nice", but worried that the bureaucratic aspect would be prohibitive. Even a simple task such as tracking fuel usage, she noted, is challenging when crew members are busy.

\section{Policy / Mandate}

Five respondents indicated that the presence of a corporate or studio policy was an opportunity for the implementation of an environmental management program on a film production. As Subject 11 noted, "all [major] studios encourage" the implementation of a program. "Encouragement" was also the term used by Subject 2, who noted a certain amount provided by the studio, although it was believed that this made it easy for a studio to pay lip service to responsibility without necessarily providing required resources. The policy opportunity is synonymous with a top down management approach, but Subject 5 noted that the presence of a policy also engendered "bottom up feedback" to help refine the program, as "they [crew members] know how to do their job better than we do." Subject 12 has gone so far as to mandate her production company to be "green" at inception; she "wants it to be part of the solution."

Respondents indicated that employee initiative characterized early environmental management efforts. The identification of a policy opportunity does seem to indicate that studios are at last responding with formal policies that encourage the behaviour (Subject 2). Interestingly, in one specific example, there was increased resistance from a set of crew members when an environmental policy was mandated in a production company, as compared to when the effort was entirely employee driven in the previous season (Subject 2).

The studios have also responded by establishing an industry committee of environmental managers representing the major studios who are working to standardize approaches and reporting techniques (Subject 3, 9). That the 
studios are cooperating on this issue suggests that there may not be any competitive advantage available in environmental management at this stage. This committee represents an opportunity as a forum for discussion, and to provide some standardization in developing policies. The environmental steward concept previously discussed also represents a policy opportunity, as studios could simply mandate the need for this resource.

\section{Non-Government Organizations}

Sector specific non-governmental organizations are driving environmental initiatives in some cases, according to Subject 1. Those NGOs are entities specifically set up to promote environmental management in the film industry, and are "equipped with resources" and "have the ability to offer guidance" (Subject 2). Green Screen Toronto is a Canadian example of this type of organization within the industry. The opportunities in these organizations exist in the outside knowledge which can be tapped.

There is at least one environmental non-government organization that does confer some recognition on film productions that satisfy their award criteria in the form of a gala event with awards (Environmental Media Association in Los Angeles), according to Subject 5; but, they do not push for compliance. They present the industry an opportunity in becoming something more than an advocate.

\section{Consumer Demand}

While one respondent believed that the "feel good imperative" of the consumer or the audience (Subject 1 ) was an opportunity, another specifically disagreed, and noted that there is not a sufficient standard of measure yet, as evidenced by a familiar and identifiable certification protocol, for there to be a "true demand" driver coming from the consumer (Subject 2).

An interview respondent also noted the lack of marketing effort being made to inform the audience about the environmental initiatives that may have taken place on a production. Subject 9 described the position of the marketing 
department when a request was made to promote the environmental achievements of a certain production as typically along the lines of "that's not what this movie is about." Promotion is star driven, and further, "the environment is not a business objective, we are in the business of making movies" (Subject 9). Subject 9 also provided an example when they approached a marketing department on a specific film that had some significant environmental achievements, and the communications department was afraid of the audience's potential negative reaction with respect to "preaching." In this specific case, there was an additional irony, as the film had related environmental content, and any reaction to "preaching" would almost certainly have come from the content rather than the production strategies.

Studios and productions are also not perceived by Subjects 1 and 9 to be implementing environmental management programs for the benefits that may accrue to the public face of the company. There is "no penalty for low environmental performance", noted Subject 1, and therefore is "not worth doing only for image." While there may be a growing awareness in the public sphere, one respondent believed that there may not a sufficient link between studio brand awareness and a particular movie for this to be an effective motivation (Subject 9). It was noted by Subject 5 that there is no brand loyalty, or even recognition, from consumers at the studio level; viewers are "content driven" in their film watching decisions, and they "could not care less" if the production company was green.

\section{Unions / Guilds / Film Schools}

Just one respondent indicated that the external unions, guilds and film schools are acting as driving forces for environmental management in the industry at large. Subject 10, a union member, indicated that the technical union she belonged to recognizes the value in having trained union personnel, and are instituting education programs as a result. She also noted that education on green filming practices is happening now in film schools, and that schools are "very receptive." 
Subject 1 believes that while there is the potential for unions and guilds to drive environmental performance on a film production, they are not pushing the agenda. Union priorities are to be supportive of their membership, and there may not yet be a connection with the environment and jobs or wage security for members. Subject 2 was more severe in his critique of the unions, saying that there is "no support whatsoever" for environmental efforts being made by the production. Not discussed was the form of support that should be provided; but given the union's role of supplying experienced crew members for various positions on a film set, the opportunity to add some basic environmental management training to a crew member's skill set may be one area a union could contribute to the implementation and success of an environmental management program.

\section{Regulation}

Subject 5 noted that it was regulation at the state level that ultimately drove certain aspects of facility operations that forced recycling requirements on Hollywood studios in the 1990s. From this perspective, regulation presents an opportunity for those films that shoot on a studio lot. State government air quality regulations also determine which products can and cannot be used on a studio lot. One result from this specific legislation was a studio policy that prohibits the use of any paint or solvent that contains volatile organic compounds (an air pollutant) and which extends to all productions at that facility as a result (Subject $5)$.

However, while a regulation violation may subject the studio or PBO to a fine, Subject 5 believes that there currently is no litigation or liability risk which acts as an environmental driver. This opportunity is strictly in the form of future environmental legislation that may require further adaptations and innovations on the part of film productions. Respondents also indicated that local governments could offer some form of tax incentive for film productions that implement some form of environmental program, as a means of helping to offset the cost (Subject 3, Subject 7). 


\subsection{Weaknesses}

There were fourteen barriers identified by the respondents, which were further classified as weaknesses and threats. Generally, the interview discussions around the topic of barriers elicited a more detailed response than the discussion around drivers.

\section{Crew Cooperation}

The overall cooperation level of a crew with an environmental management mandate was described by Subject 6 as: $15 \%$ will provide extra effort, $70 \%$ will comply if it requires no extra effort, and $15 \%$ will actively resist or even "sabotage" efforts. The respondent did note that a measure of conviction can be developed in the latter group with the full time presence of a "personable" environmental steward on set. The steward can provide knowledge, guidance, and facilitate crew adoption of environmental initiatives. One example that found success was in streaming waste around food consumption. Greater compliance was found with a steward available to provide guidance in using the appropriate waste receptacle for compost, recyclables, or garbage (Subject 7).

Subject 5 noted that environmental programs were a "tough sell in the beginning", but that things are better now. Subject 9 expanded on the challenges in the early stages of the movement, noting that there was a range of attitudes expressed by crew members, including: lack of knowledge, ignorance, and lack of interest, with a typical question being, "Why does this affect me? I'm very busy making a show."

Somewhat unexpectedly, Subject 2 indicated that he had noted a decrease in compliance year over year on a pair of productions with substantially the same crew members, which was attributed to a more management driven approach rather than the initial grassroots initiative that had characterized the first year of the program. In addition, the respondent believed the crew thought that program strategies were no more than an effort at cost savings. 
Geographical shooting jurisdiction was also described as instituting potential cooperation barriers. Subject 11, a producer, offered that as a result of the long standing union presence, the crews in New York have a different attitude towards environmental programs than those in Los Angeles, who she described as more amenable. The respondent noted that while LA crew members may be more compliant due to increased exposure, she truly believed that there was a disposition factor at work.

Cooperation between crew and studio executives is required, and the same range of attitudes is encountered. An executive may be "aware of the problem", but not sure what it means or what needs to be done to address it (Subject 9). "What it means for productions to have a reduced environmental footprint, how much is it going to cost, and what is the upside? What will it do for the movie and for the studio?" The unfortunate answer to the last question, according to the respondent, is "probably not a whole lot." The effort will not likely have any discernible benefits to the production company or the studio (Subject 9). With little benefit available, Subject 9 noted that the studio may not support their own in-house sustainability department or their efforts. A studio is very aware of things that may cast them as a less desirable production facility (Subject 9).

The most important aspect of this weakness, according to Subject 9, is that very few are willing to be the on-set champion of an environmental program, and stand up to force a change in attitude. Despite that fact, Subject 12 indicates, in their experience, people generally do not want to hurt the environment, but simply do not know what to do to protect it.

\section{Nature of the Business}

The "nature of the business" weakness goes to the heart of the process of film making. Factors that drive a production's creative choices, including plot, geographical setting, genre, budget, personnel, and schedule (to name but a few) can combine to form a very unique set of requirements. What the respondents indicated is that these requirements make certain production 
processes or choices unavoidable. For example, Subject 4 noted that filming in multiple and diverse locations makes the impacts associated with air travel unavoidable. She also noted that a crew member may desire to use a certain filming technique (choosing film over a digital process and its chemical processing requirements, or in using more power demanding lighting options). Even a typical decision process seen on a film set - which can see a director change her mind over how a scene is to be shot at the last moment - can lay waste to the best laid plans, and necessitate a rapid response by the crew to avoid a costly delay, resulting in decisions that may be the least environmentally friendly (Subject 8 ). The nature of the business that is described by respondents is one requiring an "achieve at any cost" mentality. Even budgetary concerns can take a back seat, let alone any environmental considerations, to the immediate "time pressure and chaos characteristic" (Corbett and Turco 2006, p39) of the production.

The concept of a "traveling roadshow" was used by Subject 11 to describe the process of making a film, and that transportation is the biggest challenge an environmental program faces. As described earlier, the production phase of a film shoot sees a caravan of technical trucks and crew members descending upon one or more discrete shooting locations in any single day. Locations can be a hundred miles apart, the selection of which is driven by the director's vision and set requirements. A measure of environmental impact associated with fuel and generator use as a result of this process is unavoidable. It is the also the mobile nature of the production process that makes the implementation of an environmental management program that much more challenging: waste generation and pickup sites move daily, and can cross municipal boundaries with their divergent waste processing and other bylaws, an issue also noted by Corbett and Turco (2006).

If the industry went back to a studio based production system, where movies were made only on the lot, it would be a different and simpler challenge to establish an environmental management program, indeed, some studios have 
had success in this regard (Subject 5, Subject 8); but it is the roadshow issue that makes it far more complex (Subject 11).

Moving away from the centralized studio shoot has also meant that people do not relate to the concept of storing and reusing scenic flats ${ }^{2}$ any more (Subject 11). Studios, which do have the storage space to make a reuse process possible, are not financially motivated to offer a service that facilitates production off-site (a non-revenue generating shooting location).

Shooting schedule, which can see extended lengths of shooting days occurring overnight, also poses a barrier. As an unavoidable component of the film making process, shooting at night is the nature of the business. The consequence, as described by Subject 11 , is that night shoots are draining, and have a noticeable effect on mood. Compliance with an environmental program noticeably decreased under those conditions (Subject 11).

\section{Knowledge Transfer}

The knowledge transfer barrier was specifically identified by three respondents in the interviews. All of these respondents indicated that a weakness exists with respect to the transfer of environmental knowledge into, and within, a production. Subject 1 named this weakness the "critical role of information", and the need for more reports. External organizations are needed (an environmental NGO, for example, or a union) to facilitate the development and dissemination of appropriate environmental analyses. These analyses would ultimately allow productions to identify target areas for impact reduction, and provide tracking tools.

Subject 10 identified a decreasing desire on the part of productions to hire outside environmental consultants to develop and implement an environmental management program, and that there is a discernible shift to have these efforts

\footnotetext{
${ }^{2}$ Standard sized pieces of scenery, constructed out of wood, composed of a frame with a flat surface on one side (typically plywood or luaun). Built in 4' x 8' sections, flats become the set walls when lined up, and have paint or wallpaper (or other) treatments applied as required.
} 
come from internal resources. However, the challenge facing productions for this to happen is how to transfer the consultant based knowledge to the production crew.

Not only must compliance skills and implementation techniques be transferred into a production, but those skills need to endure when the crew members begin a new production. Subject 8 noted that program adoption was impeded due to a lack of coordination between productions. A crew member may be exposed to a new and different set of environmental policies every few months (for the "daily" technical employee, who responds to short term crew needs, it may be a new production every day) when they start work on a new production. Recycling was the cited example, where bin colour or accepted materials may differ on subsequent productions, resulting in a contaminated waste stream.

Subject 2 identified the need to have unions be vocal champions for environmental management, and to actively train and educate employees in the field. The real need is to have unions act as the agents of knowledge transfer, and to treat an environmental program with the same priority as a safety program (Subject 2).

\section{Delay in Implementation}

Three respondents (Subjects 4, 11 and 12) all identified the weakness resulting from starting the implementation phase of an environmental management program too late in the film's production life cycle. "Starting at the beginning", according to Subject 12, means during the interview stage of the employee hiring process with a value evaluation. The challenges from a late implementation occur as a result of the increasing work load and time constraints for crew members in adopting program policies as the company approaches filming, and the likelihood of success for a program, if not implemented by this point, seems to deteriorate (Subject 11). 


\section{Behaviour Modification}

The behaviour modification weakness manifested in two ways during the interviews. The first example is around waste collection, where a crew member may have conflicting "rules" at home and at work (Subject 2). Materials accepted for composting may differ between the two locations, especially if the crew member lives in a different municipality from the one in which they work.

The second example was the challenge in adjusting familiar habits, such as a director's long standing habit of viewing film dailies in a dedicated trailer. The opportunity to reduce the impact of carrying the additional equipment and vehicle is available, if the director is willing to adjust her routine. There is a "need to convince people that these things are easy to do" (Subject 4).

\section{Quantification / Measurement}

Subject 1 noted that the industry still needs data on the environmental impacts of film making, and the effectiveness of emissions reduction strategies: "what gets measured, gets managed." The weakness exists from not having available figures and proven mitigation techniques.

The challenge is that industry experts are still designing spreadsheets to capture this data, which may need to be customized for each production. The lack of standardized tools to facilitate data collection and reporting acts as a barrier by necessitating additional labour (Subjects 1 and 5). This lack of efficiency adds time and cost to a manager's production budget, and becomes a cost issue as well as a knowledge issue. Subject 5 also noted that standardized reporting data set may help with marketing and public relations efforts, as studios and consumers could begin to become familiar with certain metrics.

\section{Locations Department Buy-In}

The role of one department within the production company in particular, the Locations department, plays a important role in potentially creating a weakness in a program. The Locations department is responsible for managing filming locations (including the complex arrangements surrounding waste collection and 
pick up), and absolutely needs to be "on board" (Subject 2) and involved in planning from the outset.

\subsection{Threats}

\section{Budget}

As Corbett and Turco describe it, "relentless budget pressure" (2006, p33) was the most frequently identified threat by respondents (along with service and product availability). The budget threat is created by the extra cost anticipated for resources - through products and wages - to implement an environmental program on a film production. Budgets are typically dictated and rigidly controlled by the studio, leaving little flexibility from within the PBO to implement a green program that has not been specifically allocated. Subject 7 identified the quandary that many producers find themselves in, as the budget is typically assigned to a production. At that point, it does not matter if there is a desire or a mandate to "go green," if there is not even enough money to do what is necessary to just get the sets together then there will be nothing left for any environmental use.

Subject 6 has been told by a producer on a film that "I don't want this [environmental program] to cost me a penny." The cost of such a program is realized both through the premium charged on environmentally responsible replacement products over traditional options (e.g., hybrid rental vehicles or generators equipped with scrubbers over their more conventional and familiar alternatives), and also through the additional labour costs that may be required to implement a strategy. For example, it takes longer to deconstruct a set for salvage and recycling than it does to just tear it down and throw it in waste bins (Subject 7). In addition, if you can get out of a rented studio in two days rather than four, then the two days rental fee can be a big dollar savings (Subject 7). As one interviewee from Corbett and Turco's study agreed, "it is easier and more cost effective to simply throw [sets] away than to dismantle and reuse them" (2006). However, these are not issues if the budget accounts for them. 
The departmentalized nature of a film production may also be an important aspect of this threat. Film budgets are also departmentalized, said Subject 5, and so any environmental cost savings in one department is not necessarily transferred to the cost of implementation experienced in another department. This respondent recognized that a specific environmental budget line item, against which all costs accrue, may help this issue. Budget templates, however, are provided by the studio behind the project (Subject 11), and may not include or allow the insertion of such an item.

At the same time, new technology still needs to get to the same cost point as traditional technologies (Subject 5). One clear example of this is the extra cost for a diesel generator equipped with an emissions scrubber compared with the same generator without the scrubber. Some champions recognized the need to foster a demand to continue to force prices down (Subject 11), a potential "Catch-22."

Subject 9 questioned the value of financial case studies which are frequently prepared and presented as quantifications of potential cost savings associated with a particular environmental strategy. According to the respondent, these have a minimal or negligible benefit to a production. When dealing with a blockbuster type movie budget, the financial savings associated with eliminating the use of plastic water bottles becomes trivial, and the question asked of the environmental proponent is "Why are you bothering me with this?" Corbett and Turco (2006) noted similar feedback, in that the cost savings associated with an environmental management program would have to be in the $\$ 100,000$ to $\$ 200,000$ range before a large production would actually change its behaviour.

The question of cost also impacts the production's desire to address the large impacts, or higher cost versus emissions savings initiatives. Subject 9 was asked why air travel is never targeted with an emissions reduction strategy on a production, and answered, "who's going to tell [an A-list actor] that they can't fly on a private jet?" 


\section{Service and/or Product Availability}

Many respondents cited the lack of needed environmental products or services as a threat to the implementation of a program. Hybrid rental cars, while increasingly common, are still not always available in required quantities for a film production (Subject 1).

Solid waste collection also posed a significant threat. The municipal infrastructure of various filming jurisdictions can prove problematic, as many do not offer industrial compost collection. In this respect, Halifax was "easy", and Toronto, Hungary, and Morocco "difficult" or "impossible" (Subject 4). On recycling services, the literature acknowledges the challenges that productions face in this regard:

...once a production leaves the confines of the studio
complex, the logistics of reuse and recycling become
more complex, and the volumes at any given location
become much smaller, posing significant economic
and organizational challenges for recycling on
locations. (Corbett and Turco, 2006, p30)

The end result is that the lack of a critical service provided by an external supplier can make waste diversion an arduous task (Subject 2).

Subject 5 believes that technology is the biggest threat, as there simply are not enough products and services to comprehensively address the range of wasteful activities on a film set. Biodiesel generators may be a better option than diesel generators, she continued, but natural gas or solar generators would be better still. There is also the need to improve set lighting efficiencies to reduce overall consumption (Subject 5). As Subject 8 explained, innovation is still required at the macro level, in the use of different forms of energy (e.g., solar, power drops), filming methods (e.g., lighting choices), and financial incentives that make environmental considerations a priority. Four respondents cited the untapped potential of solar energy (Subjects 5, 8, 11 and 12). 
Biodiesel is a growing technological option, with equipment (such as generators) increasingly available (Subject 11). However even Los Angeles has availability issues for this new equipment. There is also a scarcity of refueling locations (an infrastructure issue) for this type of fuel, requiring one film production to establish an on-studio refuelling station (Subject 11).

Even when a more environmentally sustainable technology is available, the lower price point for traditional options makes the shift more challenging. Even though there are an increasing number of environmentally sustainable options to use in place of the sensitive practice of using the tropical hardwood lauan on film sets, for example, the price point of lauan is still competitive enough that it is a challenging financial case to make (Subject 11). The characteristics of lauan, which is light weight, readily available, and has an exceptional ability to hold a scenic paint treatment (its tooth) (Subject 11), may mean the alternatives need to ultimately offer more than just a marginal cost saving to see an increase in utilization (Subject 11).

The availability of an organized reuse market for film supplies is also absent (Subject 7). Any such organization would hold limited ability in servicing other jurisdictions (a Los Angeles organization may not be in a position to offer support to a Toronto based production, for example), which reinforces the need for such a market in all filming locations of appreciable size.

\section{Certification}

Some respondents were blunt in their opposition to the idea of having a certification for environmental performance during film production (Subjects 4, 6 , 8,9 and 12 ), and there was a coherent refrain that the studio environmental managers were opposed to the idea of environmental certification. The reasons for this opinion were based on the fact that film productions are perceived to be very different in nature, and as such, they cannot be treated with the same environmental qualification scheme (Subject 8 , Subject 9). Some things can be quantified and measured in a standardized fashion, but there are many other 
things that are driven by unique production factors, and cannot be measured so easily or uniformly (Subject 9). These factors may be quite complex when the filming location is considered (e.g., recycling in Morocco, as mentioned earlier).

Subject 12 noted that the green initiative from the Producers Guild of America is not one that is entirely inclusive, as independent film producers are not necessarily members of that guild. The certification should, Subject 12 argued, come from a non-profit entity that is merely endorsed by an industry organization.

Subject 9 also identified the perception issue, "What are the consequences for those productions that aren't going to participate whole-heartedly?" It is impossible to sing praises without simultaneously wondering about those that are not being celebrated, and does casting those films in a negative environmental light become bad for business.

Subject 4 noted that levels of performance would need to be determined, and questioned what would happen to those productions that make sincere efforts in some areas, but cannot achieve a certification because of inherent filming requirements (i.e., the heavy emissions resulting from a large scale action movie). There is also the opposite case, where a show receives a certification despite the fact it had significant challenges in some areas of performance, and "would that really be truthful" (Subject 4). On the whole, Subject 4 believed that there were still questions to be resolved regarding the consistency and value of a potential certification.

\section{Competitive Advantage}

Three subjects noted that there is no competitive advantage available at the studio level for implementing environmental management programs. Subject 5 tied this to the fact that there is "no brand loyalty", meaning viewers are "content driven" and do not discriminate between studios. Environmental or "greening" would be the "least reason" to motivate viewers (Subject 5). This threat originates from the studios and the consumers, both external agents to the PBO. 
There was one dissenting opinion, as Subject 2 noted that doing environmental management well may be an indicator that "you can do other things well," and in this fashion appeal to producers and studios looking for a filming destination.

\section{No Environmental Line Item}

This budget formatting threat, identified by Subjects 2 and 3, focuses on being able to relate environmental management program costs across all departments to a single budgetary line item. The lack of such a line, says Subject 3 , simply makes it more challenging for a specific department to carve out the required funds against other priorities. Film budgets are prepared according to studio specifications (Subject 11), with little flexibility in adding new line items. A producer who desires to add an environmental budget item needs to obtain approvals from the studio, which are not guaranteed.

Subject 2 additionally believes that productions with extremely low budgets face additional challenges in implementing a program simply through a scarcity of budget resources; in such a case, inserting a specific line for such an effort would certainly "get flagged" by the studio during review and removed.

\section{Brand Awareness}

The question of a studio's limited brand awareness with the movie-going public was discussed earlier. People do not typically know which studio is behind a film, as recognition is tied to actors, directors, and producers (Subject 9). The threat presents as a lack of motivation for a studio to fund an environmental management program, as there is no perceived financial (or even intangible) benefit to the studio.

\section{Unions / Guilds}

While only one respondent identified a threat relating to a union or guild, the issue goes to the heart of the union's responsibilities. The issue described relates to a "craft shop", a union construction shop located on a studio lot, that produces set elements and details which are available to be purchased by any 
production. The shop is a big piece of business for the union, and this respondent had noted resistance to the introduction of a new sustainable product because it had the potential to result in craft shop job losses (Subject 5).

\section{Government Agencies}

Subject 1 provided an example of this threat as it applied at a regional film council level. The threat manifested itself through an industry environmental committee on sustainability, where the regional film council exercised a heavy influence on the scope of research to be undertaken was under discussion. The sustainability concept was seen to present a risk to securing new film production business in a certain jurisdiction, as producers may interpret an initiative instead as a mandate to "film green." The risk to revenue dollars provided the basis for the threat posed by the film council, which actively worked to water down any initiatives put forward.

\section{Studio Issues}

There was a question raised around the studios' existing sustainability departments, and whether the role is one of policy implementation or as a resource (Subject 9). The respondent noted that pushing an environmental agenda on the jurisdictional footprint of the studio can present a threat to a production company "client" who is simply leasing space on the lot. If the production is unwilling to cooperate, the sustainability department is sometimes not supported by the studio in any type of enforcement action (Subject 9). The studio recognizes the revenue dollar of the client production, and is loathe to put it at risk. In this fashion, reluctant PBOs can cannibalize the efforts of a PBO with an environmental program. 


\subsection{DISCUSSION}

\subsection{Strengths and Opportunities}

The results indicate that strengths were identified slightly more frequently than opportunities. It is possible that interviewees simply did not recognize opportunities as readily as they did strengths, or that strengths are simply more numerous. However, one wonders if it may be possible that there are relatively fewer external opportunities to drive environmental management within film production.

The impetus for environmental management seems currently to be coming primarily from within the PBO itself, as manifested through the identified strengths. At present, social conscience is the foremost reason. According to what was identified by the respondents, the opportunities presented by regulation, environmental organizations, government, unions and guilds, and consumer demand are yet to become realized, and are not yet significant factors in driving environmental performance. Recall that Thuvander et al. (2011) also indicated that environmental management in the construction industry is still in a self-regulation phase, and that market forces are not yet the dominant environmental driver in the industry. While regulations are certainly a consideration for any construction project, regulatory compliance was mentioned last in a list of relative benefits for environmental performance by Shen and Tam (2002). Government regulations may not yet be an opportunity that has been tapped by the construction industry at this point either.

Policy and the desire for certification are the only opportunities that are having any real effect. Subject 5 noted that there has recently been some formal policy development on the part of the studios, which is flowing down to the PBO. Already a factor, this opportunity may continue to grow with time. Some PBOs have also pursued an environmental certification through the Environmental Media Association, and while numbers of certified productions are increasing, they still numbered only 22 in 2011 (EMA n.d. c). 
The seeming lack of opportunities may be a reflection of the overall lack of maturity of the environmental initiative within the industry. Corbett and Turco (2006) noted the relatively slow entrenchment process that has characterized environmental management in the film industry. This observation is supported by the fact that some five years after that report, the number of certified productions is still relatively minimal.

The question of whether operational strengths are sufficient for developing widespread uptake and long term success of environmental management is a critical one. This is not a topic that was specifically researched in the literature review, but would be a germane topic for further investigation. It may benefit film industry professionals to look towards external permanent structures (e.g., film schools, unions, guilds, government and non-governmental organizations) to develop further incentive sources. A financial incentive or disincentive to the PBO surrounding compliance via a tax break, for example, as noted by Subject 1 and Subject 10, may be the kind of opportunity that would accelerate program development and implementation.

\subsubsection{Strength: Social Conscience}

The reduction of environmental impacts associated with the construction industry was identified consistently in the literature as the most significant driver for environmental management (Shen and Tam 2002; Augenbroe and Pearce 1998; Manoliadis et al. 2006). The motivation for the construction industry's efforts is coming from its position as a major polluter and user of natural resources (Augenbroe and Pearce 1998), and could be a practical response rather than a moral one on the part of developers and owners.

The interview results identified the "social conscience" strength most frequently, and that reducing environmental impacts is the right thing to do. Whether motivated by a moral or a practical imperative, stakeholders in both industries are certainly of the same mind that the need to protect the environment is an important reason to act sustainably. 
The long term prospects of the industry's environmental management efforts need to rest on more than the social conscience of a strong willed section of its employees. Other motivations so seem to be arising, as seen by studio policy development (and the creation of sustainability departments within their structures). Talent incentive has proved to be a successful strength when available, and could be one that offers more potential. This is still a largely untapped resource - actors hold significant power in the PBO structure, and could see their public image benefit from being seen as an environmental advocate. Environmental proponents in the industry would do well to target A-list actors to make some form of environmental management a "must have" to ensure their participation on a production.

\subsubsection{Opportunity: Corporate Image}

Corporate image is an important opportunity discussed in the construction industry literature that was not identified in the interview results. Thuvander et al.'s (2011) study on the construction industry indicated that $85 \%$ of subjects in their research identified a positive effect to the company's image. Shen and Tam (2002) cite this opportunity as the third most important in their results, after environmental protection and reduced environmental risks. Yet no respondents from the film industry identified corporate image when asked to identify drivers of environmental management.

From a PBO perspective, the film industry result might be expected: with no permanent organization present, where would the corporate image benefits accrue? This result would be expected to repeat in the construction industry case, if the PBO comparison holds true across industries, but only Manoliadis et al. (2006) did not identify a corporate image driver in the results of their survey.

The respondents specifically discussed the lack of connection between the PBO and the studio behind the production in the eyes of consumers. One possible explanation for the results in Thuvander et al. (2011) and Shen and Tam 
(2002) is that construction PBOs may represent their respective parent company to a greater degree than in the film case.

Construction firms are, like film studios, permanent entities; it is their respective projects that are temporary. However, the business objectives of the PBO in the two industries are not perfectly aligned. If a developer is seeking a firm to construct a hospital with an environmental certification, they would be advised to seek a contractor with tangible achievements in that specific endeavour. A potential project proponent's past success in sustainable building would be germane and subject to evaluation. The same is not quite true in the film industry, where the final product is much closer to a commodity. The economic demand for a building with sustainability characteristics is greater than the economic demand for a film production with an environmental certification attached - no one is asking for movies to have an environmental certification. Some interview respondents noted this demand was non-existent. As a counter example, however, one needs only look to the Responsible Care initiative (International Council of Chemical Associations 2013) to find an example of an industry established social responsibility standard (which includes an environmental component) created in the absence of economic demand; however, there has not been a similarly sized disaster (see Bhopal) to help motivate its formation in the film industry.

\subsubsection{Opportunities Not Identified}

There were additional construction industry opportunities that were not identified in the film interviews. Shen and Tam (2002) indicated improved public environmental standards is an opportunity, and Manoliadis (2006) identified the need for product innovation, new kinds of partnerships and stakeholders, proactive role of materials manufacturing, and recognition of commercial buildings as productivity assets. Upon review of these construction-based opportunities, product innovation and new kinds of partnerships are certainly extendable to the film case. However, the balance are likely not transferable across industries. 


\subsection{Weaknesses and Threats}

There is some similarity between the construction weaknesses derived from the literature and those revealed for film in the interview results, foremost being the crew cooperation weakness. Threats were also common to the two industries, as cost and service and product availability were found in both industries.

\subsubsection{Weakness: Crew Cooperation}

Crew cooperation was the most frequently cited weakness. Some of this weakness may have been the initial novelty for these programs in the industry in general (Subject 5), and that compliance is growing with increased familiarity. We have seen that it is possible to offset this weakness with the champion strength, or by having an environmental steward on the production. The challenges presented by this weakness may be addressed with the right resources.

Crew composition is different between productions, and as such, so too may be their resistance to an environmental management effort. Subject 11 noted a perceived difference between crew members based in New York and Los Angeles. Subject 2 noted that when the environmental management program was perceived as being a mandated policy, compliance actually decreased from the prior year, when it was an employee initiative. It may be important to keep the crew actively involved with the development of policies, as a matter of engagement and ownership.

The construction industry literature also identified lack of crew cooperation as a weakness. However, this may not be a weakness limited to just the PBO structure, as even permanent organizations would experience issues with respect to compliance and behaviour modification. Traditional approaches to overcoming this weakness - training, education, communication - may be sufficient to address it in the film PBO as well. 


\subsubsection{Threat: Budget}

Thuvander et al. (2011) consider the cost barrier to be a weakness whereas in this analysis it has been classified as a threat. The allocation of funds against costs is reasonably construed as being within the executive control of the PBO (and therefore a weakness). The choice to spend on a sustainability initiative would simply need to become a factor in the overall budget allowance. However, the manner in which projects are secured by the PBOs makes this a different issue between the two industries. The decision to classify cost as a threat in this analysis was based on the fact that the funding for a film production is not generated from within the PBO - it is provided from an external source (the studio), and environmental management is not typically within the scope of spending for those funds. In contrast, when bidding for a construction project, environmental costs will be specifically accounted, as the design specifications will make this a requirement.

This is where the limitation occurs, in that if funds were added for discretionary environmental spending in a film budget, that threat would be largely overcome. The line is admittedly not so clear cut, and further stresses the importance of what the interview respondents identified as the dedicated budgetary line item opportunity for environmental programs assigned by the studio.

\subsubsection{Threat: Competitive Advantage}

Three interview respondents noted that there was no competitive advantage available to the film industry through environmental management. This threat aligns with Thuvander et al.'s (2011) research on the construction industry. Employees in the film industry are an important knowledge repository for environmental management strategies. The mobile nature of employees in the film industry - driven by the PBO structure - removes a key pillar in the studio's ability to develop a sustained competitive advantage (Barney 1991). This knowledge is essentially mobile, and becomes immediately available to competing studios upon the PBO's dissolution. Subject 5 made this observation, 
and concluded additionally that there was no advantage to being an early adopter. She also noted that this employee mobility has essentially created some value for the studios to move in coordinated fashion, one motivation for the creation of the environmental committee on which sustainability department heads from the studios sit.

\subsubsection{Threat: Service and Product Availability}

A lack of infrastructure poses a huge threat to environmental management in the film industry, just as it does to the construction industry. Interview subjects noted that services such as recycling and organics collection are absent in many localities, and at a minimum, differ in the waste streams that they collect. There is certainly a gap between infrastructure development and the requirements of the film production, given that productions struggle to recycle huge volumes of gently used set construction materials (Subject 1). One simple reason is that municipal bylaws (and higher levels of government regulation) are unlikely to consistently align with the recycling requirements of a film production.

Construction needs to address this same threat, as each new project may occur in a different municipality, with different regulations on waste handling. The construction case is even more challenging, in that it requires not just disposal of construction waste, but working with government agencies at all levels on the development and access to civilian infrastructure needs such as sanitation, transit, water, and utilities. How construction is able to address this threat was not revealed in the literature.

There is also the need for product development in the film case. An alternative to lauan and an untapped solar energy potential as an electrical power source were two areas that were specifically cited by the respondents. Innovation on the environmental front would be helpful to advance these aspects of environmental management on film productions. 


\subsection{Stakeholder Interests}

The stakeholders in a construction project change through its life cycle. A building might be commissioned by the real estate owner, constructed by a developer (who in turn hires an architect and a general contractor, and secures financing or investment). There is some ambiguity in trying to identify who the consumer is in this life cycle, and delivering on their environmental performance expectations. The general contractor is motivated to deliver a building that meets legal and safety requirements, and meets the design specifications of the developer at the lowest possible cost (Van Bueren and Priemus 2002). The environmental motivations of the tenant may not align with those of the real estate owner, and may be even further from the environmental motivations of the general contractor.

This is the worst possible case from a sustainability perspective, where environmental measures need to be established at an early decision making phase. Feedback from an occupying tenant has little value when the building is already built. The fundamental problem is that the interests of the stakeholders at each stage do not align. Van Bueren and Priemus (2002) describe this as the gap between construction and management.

This same issue emerged through the interviews as well, including the same confusion over the definition of who the consumer really is: the studio, who has often commissioned, financed, and owns the work; or the audience member, who ultimately pays the studio for access to the product in a theatre or other setting.

As Subject 9 noted, studios are "in the business of making movies." The primary goal of the PBO is to deliver a completed movie to the studio, and environmental motivations may be tangential to that outcome. Just as in the construction life cycle, there exist further intermediary stakeholders in the film production life cycle, each of which may value environmental performance to a different extent, including the distributor and the exhibitor (theatre chain, airline, or cable channel). 
The construction literature indicates that there is a price premium that can be realized from the final consumer (the tenant) of a building that has certain environmental performance standards. This represents a financial signal that is flowing from the tenant back through the intermediary stakeholders in a construction project to the real estate owner. There is a financial feedback mechanism in place.

To compare industries, the final tenant in a construction project is at the same stage of the life cycle as the audience member in the theatre. Film goers do not have an option to pay a price premium for a film that incorporates environmental concerns in their production process - nor is there any indication that they would be willing to pay such a premium. The same feedback mechanism does not exist in the film industry, and is one that may be of value if it was to be created. A consumer driven opportunity such as this may offer an incentive to film studios to produce films in an environmentally friendly fashion.

Thuvander (2011) cites a lack of clear regulations and a lack of regulatory incentives as two government-based threats to environmental management in the construction industry. The role of government is also underdeveloped in the matter of environmental management in film production, although this varies based on jurisdiction. In general, respondents noted that a tax incentive to the PBO could be offered as a means of offsetting some of the costs of an environmental program. Regulation has also played a role (the waste diversion regulations in California, for example) in advancing environmental performance in some areas, so there is potential through legislation. This example also shows that regulation does not even need to be specific to film production, as the PBO will need to respond to broader legislation just like any other entity.

\subsection{Project-Based Organizations}

Issues relating to the project-based nature of film production were both explicitly and implicitly revealed through the interviews. The literature review 
identified several implications of the PBO structure that would be expected results of the interviews, namely innovation and knowledge transfer.

\subsubsection{Innovation}

The existence of the service and product availability threat offers some support for the need for innovative solutions to the environmental issues being encountered on film productions.

The lack of opportunity for research and development is a signature characteristic of the PBO (Bayer and Gann 2007). In the construction case, Hartmann (2006) indicated the need for both an ability to innovate via resource availability, and a willingness to innovate via corporate culture. The literature also proposes the idea of organizational slack as a means of driving innovation in construction firms. Slack is a level of resources that exists beyond that required to produce a given level of organizational output (Nohria and Gulati 1997). Innovative construction companies would develop and embed slack resources as a matter of corporate culture, in order to nurture that innovative behaviour (Horsthuis et al. 2012).

Based on the results of the interviews, this does not appear to be the case in film production. The excess of resources required for innovation on the environmental front is simply not there. From Hartmann (2006), this would preclude an ability to innovate. There is an argument to be made that the sporadic filming bursts of a production day may somehow be able to offer the excess of labour that would be required during periods of downtime; recall that Bechky (2006) noted the critical role downtime already plays in relationship development and networking. With no evidence of innovation occurring, the limiting factor may be one of capital, or of the availability of the right kind of labour.

The film PBO may simply not be the right place for product development to occur, given its intense focus on other tasks. This fact, however, is exactly the structural inhibitor that the PBO represents. It is an organizational form that does 
not allow for non-critical tasks to be undertaken, as there are always constraints on resources, time, labour, and matters of priority. There is also not necessarily a need for the film PBO to undertake innovation itself, as there are other structures available. Environmental NGOs, jurisdictional film councils, unions, guilds, government agencies, academia and the studios themselves all present themselves as potential opportunities for sources of innovation. The carbon tracking solution which was developed by the environmental committee composed of studio sustainability managers is an excellent example of the innovation potential that a permanent structure can provide, but not all are at this level of preparedness and usefulness. However, the PBO needs to be more dependent on external sources of innovation to address shortfalls in environmental products and services.

\subsubsection{Knowledge Transfer}

Knowledge transfer has been identified in the literature and interviews as a barrier for the project-based organization (Ferriani et al. 2005; Hobday 2000). The issue revealed in the literature is the question around where the new knowledge resides. In the film case, a number of industry-related knowledge repositories are available: the permanent structures of the guilds and unions, the contract employees of the PBO, non-governmental organizations and government funded film councils, and the managers in the permanent studio parent. Environmental consultancies would be an example of a knowledge repository that exists outside the industry. These structures are all designed to be perpetual entities - they outlive the PBO.

As representatives of various employee classes, the guilds and unions typically have educational and training systems of varying sophistication embedded in their structures. It was suggested during the interviews (and in Felder et al. 2009) that the unions and guilds could begin to treat environmental management in the same fashion that safety or first aid is treated now, resulting in trained and certified employees with this expertise. This training program could form the basis of a certification for future environmental stewards, the 
specifically trained or experienced employees who have a sole responsibility of implementing and monitoring the environmental program on a film set.

This leads to the second repository, which are the employees themselves. The film industry is one that is heavily based on apprenticeship (Corbett and Turco 2006, Bechky 2006), where technical knowledge comes from role models or mentors. To be successful, it has been argued that environmental management strategies need to filter down through these role relationships just like a technical skill (Corbett and Turco 2006). This informational flow was described during the interviews. Respondents clarified that even when there was no top-down management driven environmental policy in place, there was an absolute requirement to have one of the key executives onside with the environmental initiative (the producer, director, or the production manager) to act as a champion. This was primarily an approval issue which aligns with Thuvander's (2011) note on the overall influence connected to the champion position in the construction industry. This authority allows crew members the ability to implement the required environmental strategies. If an environmental consultant was brought in, one avenue employed was to relay information to the department heads, allowing practical knowledge to be disseminated to the whole crew through the traditional relationship structure.

In an initial vacuum of well trained and knowledgeable senior crew members, environmental knowledge could be transferred via an external agency - such as the union - through a structured training program. Once that base of knowledge has been firmly established, the traditional apprenticeship knowledge transfer model can apply.

An employee is the mobile element between PBOs, and is therefore also capable of carrying environmental knowledge on to a new production. With the right empowerment, these employees could implement and train each new set of cohorts. This strategy is gaining some formal traction in the form of environmental stewards. As indicated by some of the respondents, the presence 
of an environmental steward is a budgetary opportunity, requiring funds to pay wages over the course of a production. These funds, however, are not always available.

Regardless of how they obtained this knowledge initially, these stewards also have the benefit of a third knowledge repository for assistance: the studio's sustainability departments. These managers are also collecting data, and working to refine strategies and develop new ones. Subject 6 noted that the knowledge transfer weakness was being addressed through the studio structure itself, via an industry committee composed of the managers of the studios' sustainability departments. This external repository is the result of increased interest in environmental management from the studios, and has resulted in a top down management approach as programs are pushed onto production entities (Subject 6).

Subject 4 noted that while most production companies are "one-off" entities, they are formed by parent companies that typically have an ongoing commitment to certain environmental practices. The PBO entity may or may not benefit from this commitment; they may receive resource support or a policy directive through sustainability offices that exist at most of these companies, but as Subject 5 noted, that support is never guaranteed. The reason behind the lack of support was identified in the interview as the priority given to the revenue generating client against the interests of the sustainability department - and even the broader environmental goals of the studio organization. Subject 5 noted that a studio leases its space to PBOs (who may or may not be making a film on the studios slate). The studios have no desire to appear inhospitable to a PBO on the lot through stringent environmental controls, and according to Subject 5 , will sacrifice an environmental enforcement action to the benefit of the client.

It would be expected that a publically traded entertainment conglomerate would have certain environmental goals as part of a broader corporate social responsibility (CSR) initiative. It is interesting to note that the studios may be 
impinging their own CSR efforts through a lack of focus on the emissions of the film production process on their properties.

A fourth knowledge repository is the government and non-governmental organizations that publish green production and resource guides. New Zealand (NZMOE 2005), British Columbia (British Columbia Film Commission 2011), Toronto (Felder et al. 2008a), and London (Greater London Authority 2009) have all used government funding to prepare and publish a version of these guides. While their motives have arguably been primarily for business development, these guides have thus far been the most tangible output of the industry's environmental management efforts. Government funding has thus far been critical to codifying existing practices.

From all appearances, the film industry has been making strides in overcoming the limitations of the PBO in the form of knowledge transfer, making use of employees as knowledge repositories (the environmental steward, for example). Where it is not succeeding is the innovation front. It is unlikely that the corporate culture of film production will ever change sufficiently to allow for in situ research and development; as a result, other entities need to assume this responsibility. The unions and guilds, if they begin to incorporate a more generalized environmental training regimen, may find the opportunity to spend some time improving and innovating on the very skills they are teaching. Workshops and seminars organized by a studio consortium, film school, or nongovernmental organization are another potential avenue for innovation, which could bring together students, employees, and managers in a constructive atmosphere.

\subsubsection{Comparing Strengths and Opportunities with the Permanent Organization}

Permanent organizations are motivated by three primary forces in their ecological responsiveness efforts: competitiveness, legitimation, and ecological responsibility (Bansal and Roth 2000). Gaining competitive advantage through 
environmental responsibility can occur by lowering costs, improving reputation, or adding a revenue source, among other options (Bansal and Roth 2000). The opinion of some interview respondents is that the available window for a return on environmental investment is too short: for example, there is not enough cost savings over the course of a production to justify switching to a hybrid vehicle as "you just don't drive enough" (Subject 11). The reputational benefit is one that the various film jurisdictions have attempted to pursue, but it is not one that is being sought at the PBO level. Finally, is the noted challenge of innovation in the film PBO: Bansal and Roth (2000) note that competitiveness is an innovation driver in the permanent organizations that they studied. There is no evidence from the interviews that the PBOs exhibit the same behaviour, however.

To this point, motivations under discussion have largely been financial in nature. Others certainly exist: ease of securing filming permits, attracting higher calibre cast or crew members, and even developing operating efficiencies within the PBO. However, none of these other motivations were identified during the interviews. Cost, on the other hand, was a constant focus of discussion.

Legitimacy is the question of long term survival, and in similar fashion, the dimensions of that motivation are absent in the film PBO. While long term survival is a motivation for the studio, firm survival and risks of noncompliance were not identified as drivers in the interviews, and just one respondent each noted compliance with regulation (Subject 4), and early adopter advantage (Subject 5) as drivers (as a strength and an opportunity respectively). Like competitiveness, legitimacy is a long term organizational consideration which drives ecological responsibility. In contrast to permanent organizations, little evidence was found through the interviews that these exist in the film PBO.

However, there is agreement with Bansal and Roth's (2000) third motivation, social responsibility. The theme of social obligation, or the right thing to do, was the most frequently identified strength of the film PBO for environmental responsibility. 


\subsubsection{Comparison Industry Review}

The selection of construction as a comparator industry for the research was suggested by the literature's presentation of the industry as an example of project-based enterprise. The ready availability of literature related to the construction industry's environmental management efforts was also an important consideration. After conducting the interviews and contrasting with the construction literature, it is appropriate to review the characteristics of the comparison, given that there are important aspects of each industry that are unique, which are summarized in Table 9.

Table 9

Film and construction industry comparison review

\begin{tabular}{lll}
\hline & Film Industry & Construction Industry \\
\hline $\begin{array}{l}\text { Procurement } \\
\text { Process }\end{array}$ & $\begin{array}{l}\text { Typically commissioned with } \\
\text { a budget allocated by a } \\
\text { studio. }\end{array}$ & $\begin{array}{l}\text { Multiple procurement methods } \\
\text { available, but typically involves } \\
\text { a bid process. }\end{array}$ \\
\hline Location & $\begin{array}{l}\text { Possible to have multiple } \\
\text { filming locations over course } \\
\text { of production. }\end{array}$ & $\begin{array}{l}\text { Location does not change over } \\
\text { course of construction. }\end{array}$ \\
\hline Output & $\begin{array}{l}\text { Rare to have environmental } \\
\text { performance made a } \\
\text { specified output. }\end{array}$ & $\begin{array}{l}\text { Not uncommon to have } \\
\text { environmental performance } \\
\text { made a specified output of the } \\
\text { project (i.e., LEED certification). }\end{array}$ \\
\hline
\end{tabular}

The procurement process for each industry is different. Where a film will be greenlit and budgeted primarily by the studio's internal considerations, the construction process will see competing construction firms bidding to an owner for the work. This difference gives a construction firm the discretion to include a budget for any desired (or required) environmental management, which is not available in film.

Location is an important characteristic that may have some impact on the variance in challenges experienced by each industry. As was discussed in the 
film case, shooting in multiple discrete locations in the same evening presents infrastructure demands related to waste handling. The significance of the environmental impacts in a film production are also heavily dependent on its mobile nature, with greenhouse gas emissions (as an example) a necessary consequence from moving the entire cast and crew apparatus between (sometimes) distant filming locations. This does make the film case different from the construction case, where the entire construction project will occur in one location.

Finally, when a LEED or Energy Star certification is specified in the design of a project, the contractor is expected to budget for the environmental requirements of the project at the outset. This would be expected to remove a significant threat in the form of budget. The same opportunity - to budget in advance for the environmental requirements of a production - is not typically available in the film industry.

\subsection{Certification}

It is an interesting contradiction that many of the interview subjects found great challenges to the idea of certification as a means of driving or celebrating a level of environmental performance achieved during film production. The reasons identified were varied: the unique nature of each production, standardization challenges, and the negative perception risk. It is for these reasons, that, when asked, a number of respondents (Subjects 4, 6, 9) were directly opposed to certification, and even more (Subjects $1,5,7,8,11,12$ ) questioned its value for the film industry.

It was noted by one subject that certification could be an avenue by which brand benefits begin to accrue, as the value of the certification "grows over time" (Subject 1). This does not address the obvious PBO barrier, which is how to tie the benefits of certification back to the parent studio entity, as we have seen that there is low brand awareness on the part of consumers to the studio behind a film production. Pursuing a certification would incur some cost to the PBO in the area of program design, monitoring, reporting, and/or verification. Cost was 
already identified as the most significant threat to environmental management in film during the interviews, and a certification program would only increase that threat.

The Green Seal program is a readily available certification option currently available for film producers through the Environmental Media Association (Environmental Media Association n.d. a), so there is even a model of what certification looks like. Despite being a certification program available and with a measure of profile attached (through gala events and "A-list" celebrity support), it has not seen widespread adoption. In contrast, the growth in LEED and Energy Star certified buildings is geometric, doubling almost every two years (Fuerst and McAllister 2011). Additional incentives appear to still be required for certification schemes to attract the attention of film producers. 


\subsection{CONCLUSIONS}

The purpose of this research is to examine the current state of the film industry's environmental management efforts, by using the temporary structure of the production itself as a framework. First, what motivations exist for the projectbased organization to expend resources to implement an environmental management program? Second, do the barriers identified for the film industry align with those that are predicted by a review of the project-based literature, and with those experienced by the project-based organizations in the construction industry?

Gateway objectives were established to provide a path towards understanding how the film project-based organization is addressing the limitations of its structure, as it applies to environmental management.

- What are the strengths, weaknesses, opportunities and threats in implementing environmental management on a film production?

- How do the identified weaknesses and threats relate to the projectbased organization structure in the film industry?

- What strengths, weaknesses, opportunities, and threats exist in implementing environmental management in the construction industry? How do those compare to the film industry?

\subsection{Environmental Management SWOT Analysis for Film PBOs}

The most frequently identified strengths were those of social conscience and the presence of a program champion. At present, the overwhelming strength of the film PBO in pursuing environmental management is the social conscience of its employees. The long term prospects of environmental efforts needs to build on this strength, and take advantage of some of the opportunities that were identified. A critical success factor was deemed to be the need for the support of a high profile program proponent, or program champion, which would be a director, producer, or environmental steward. This allows for a direct line of authority to drive crew behaviour, which was identified as the largest weakness 
to environmental management.

There is some evidence that new opportunities are developing, specifically policy development by the studios and the desire for a certification protocol. Most of the studios now employ managers in sustainability departments, who are charged with developing and implementing environmental policies on the PBOs they commission. Environmental certification of a film is available in the industry, is increasingly pursued by productions, though not yet in sizable numbers. Certification did not have unanimous support among the respondents, however, who cited challenges in standardizing seemingly diverse film projects, and the negative perception risk for those films that do not pursue or achieve the certification.

The most frequently cited weaknesses were crew cooperation and the nature of the business. The most important aspect of crew cooperation is that few members are willing to act as the on-set champion of the environmental program. Compliance was noted to increase when there was a full time environmental steward present. The nature of the business weakness revolved around the idea of a film production as a traveling roadshow, driven by extremely tight cost and scheduling constraints. The interview respondents also believe that the process of film making is driven by creative and financial forces that serve to make each production unique, and thereby offering a unique set of environmental challenges that resist a standardized approach. There is no reason to believe that the challenges experienced by the construction industry would be otherwise, where a standardized approach (in the form of LEED and Energy Star certifications) has met with some success.

The most frequently cited threat facing a PBO according to respondents is the lack of financial resources to design, implement, monitor and report on an environmental management program. Product and service availability was just as frequently cited, a key example of which is the lack of appropriate infrastructure (typically municipally based) to handle certain waste streams. 


\subsection{Weaknesses and Threats and the PBO}

The literature review provided a basis to identify expected organizational limitations of the PBO. These issues included the barriers of innovation and knowledge transfer. The interviews revealed very real challenges in both of these areas.

Environmental management in film production have thus far been largely developed as a result of external funding initiatives to consultants, and have been done so largely on a jurisdictional basis (Los Angeles, Toronto, New Zealand, London, for example) in an effort to foster a competitive advantage for that filming destination. However, this funding is irregular, making research and development efforts - the genesis for innovation - sporadic. While the basic elements of environmental management have likely been, further development opportunities remain, such as the development of tracking and reporting assets, or the refinement of a certification protocol. The PBO, at least in the film case, may need to become more reliant on external sources of innovation than a permanent organization. The roles of unions, guilds, studios, and even film schools - some of the permanent organizational entities in the film production economy - need to expand to include an environmental mandate, including research and development activities.

Knowledge transfer is another predicted barrier for the PBO, and interview respondents noted that the lack of service and product availability is a threat, and knowledge transfer a weakness. The research identified at least four potential repositories of knowledge that are available to the industry to sustain and convey environmental skills. Those repositories are the unions and guilds, the contract employees of the PBO, non-governmental organizations and government funded film councils, and the managers in the permanent studio parent. Respondents noted a need to expand their environmental mandate to also include education and training. The notion of the union being able to certify technical employees with certain skills in the environmental arena as well is a good one. A general recommendation to practitioners is to take advantage of the opportunities for 
training and knowledge transfer presented by the permanent entities within the industry.

Being mobile, employees themselves can also act as knowledge repositories, carrying information between projects. Some success is already being seen in this fashion with environmental stewards, whose responsibility it is to implement and monitor environmental programs in the PBO. The studios ability to transfer knowledge through permanent in-house sustainability departments is also an important transfer mechanism, which is being used to greater effect through policy development. Green resource guides published by non-governmental and governmental agencies alike have also served to codify existing practices, and are available to future PBOs.

\subsection{Environmental Management SWOT Analysis for Construction PBOs}

The construction industry strengths and opportunities were developed from the drivers identified in the literature. Augenbroe and Pearce (1998) noted the environmental consequences of construction, and a desire to alleviate those effects as principal strengths; these corresponded neatly with the social conscience strength identified in the interviews. Additional strengths identified in Thuvander et al. (2011) included cost savings, which was also identified by a minority of interview respondents. While there was some alignment between the identified strengths and opportunities between the two industries, the divergences were also relevant and informative: company image and competitive advantage were strengths that were specifically identified as important considerations in the construction case, but not a single interview respondent indicated these as opportunities.

Construction threats and weaknesses were also developed from the literature, and aligned explicitly with many identified in the interviews. The literature identified a key issue in the construction industry: that stakeholders change over the course of a construction project. As a result, business objectives evolve as well, and there often exists a gap between the objectives of the final stakeholders (the tenant) and the initial stakeholders (the developers or 
construction company). In the case of environmental management, it becomes a challenge for the construction company to reconcile the business case for implementing a sustainability measure on a project with the tenant's desire to use that measure.

An ability to recover the cost of implementation from the consumer becomes an important consideration, but one that is not always straightforward, given the complexity involved with identifying who really is the final consumer. There is evidence that rental premiums obtained from real estate tenants in LEED and Energy Star certified buildings provide a price signal that is being fed back through construction project stakeholders, possibly fostering demand for more environmentally certified buildings. The same mechanism is unavailable in the film industry, which is governed by similarly complex stakeholder relationships. At present, there does not seem to be a way to access the audience member's demand for environmentally responsible film making, if it even exists.

While the financial incentives have been emphasized throughout this research, it is because other possible environmental management motivations such as reputational benefit, ease of obtaining filming permits, or attracting talent or crew members - were not revealed during the interviews.

One possibility to address this concern is the use of certification to attract other stakeholders' attention. It was clear from the interview results, however, that there are ongoing challenges in the use of such a system given the nature of the business, and unique characteristics of each film. While there are certification options currently available to the film production industry, and even an environmental management system (BS 8909), none have seen widespread adoption at this point.

There has been some discernable progress in recent years with the advent of the concept of "environmental stewards", more sophisticated tracking and reporting tools, and most importantly, the increased buy-in being seen from the major studios, with dedicated departments and managers. Sustainability, 
according to the respondents, is no longer a strange word in the film PBO. However, the results of this research indicate that structural barriers exist, and perhaps even a missing incentive. The development of environmental management in film has thus far primarily been the result of the internal strengths of the PBO, the social conscience of dedicated professionals in the industry. Wide spread adoption and further development, however, may require capitalizing on other opportunities.

\subsection{Contribution}

There is very little research of an academic standard that has been done on the film industry and its environmental management efforts. Most of the relevant material has been developed by independent consultants, on behalf of various film jurisdictions, and is focused more on practical and employable environmental management strategies. While valuable for their operational use, it does leave room for this research, which has made an initial contribution by seeking to understand some of the broader challenges and motivations in pursuing sustainability. While drivers and barriers to sustainability in film production have been discussed elsewhere, this is the first research to conduct a SWOT analysis.

The supporting literature is beginning to flush out drivers and barriers to sustainable film production. The literature also clearly establishes that film production can be considered a form of project-based enterprise. More than one researcher has suggested that the PBO nature of film production may have significant impact in the creation of those drivers and barriers. As the first to use the project-based nature of film as an analysis framework for environmental management in the industry, this research may offer some stronger evidence that the nature of the drivers and barriers is truly a result of the structure of the organization, as has been suggested.

The research situates the environmental management efforts of the film industry by specifically comparing it to another project-based industry, the 
construction industry. The comparison illustrates the similarities and differences between the application of environmental management in the two industries, and most importantly, highlights the critical role that the ultimate consumer plays in creating an overall demand and financial driver for implementing these types of initiatives. Finally, this research appears to be the first that might be applied to the general case of the environmental management concerns of the projectbased organization.

\subsection{Future Research Opportunities}

Future research opportunities can begin at a point of knowing that there may be no need to reinvent the wheel when it comes to developing a baseline environmental program for film productions. Further case studies on specific project-based industries' environmental management efforts may lead to broader PBO generalizations, and in turn to applications to the film production context. Winning strategies, criteria for success, and lessons learned could all be identified and transferred from the software industry, from complex product project teams, as well as from the construction and event planning industry.

More work also remains to be done in terms of simply identifying and quantifying the environmental impacts associated with film production, at the regional, national, and global level. Academic research on topics related to environmental management in film production is lacking, and one departure point from this research would be to determine the level of consumer demand for an environmental certification, which would be helpful to certification proponents and studios. The consumer appetite for an environmental certification, and whether it can be transferred into revenue dollars, would have important consequences for the film PBO's appetite in implementing environmental strategies.

The film interview respondents raised a number of barriers that were identified in the construction industry literature. It may be a worthwhile exercise to expand the scope of research to include a number of additional project-based industries, adding a control group of permanent industries, and determine if the 
identified barriers are a function of project structure, initiative type (i.e., environmental management), or simply general business considerations. This would build on the current research which used academic references for the comparison.

An in depth case study on a film project implementing an environmental management program may provide some further insight into how barriers manifest themselves, and how they are managed and overcome. The assumption that combines the film and television production industries could also be challenged by making it a specific basis of comparison in a future study.

A life cycle assessment approach, one which follows a film from inception to consumption by the final audience, has also still not been completed. The environmental impacts associated with production are beginning to be known, but those from distribution, sales, and exhibition warrant further investigation. This may also improve the basis of comparison with other industries. 


\section{Appendix A: Interview Template}

RYERSON

UNIVERSITY

\section{$\underline{\text { Interview Template }}$}

\section{Historical Context}

- How would you characterize the attitude of the industry towards sustainability?

- Has there been a change in attitude, the result of:

- Grassroots efforts

- Jurisdictional efforts

- Studio efforts

\section{Current State of the Industry}

- How well do you believe the industry is currently managing its impacts?

- Which environmental management tools are currently being used by the industry

- Do one of these tools or frameworks lend itself to working in the film industry better than the others?

- Is there a reasonable expense level for an environmental program? Should one be mandatory?

\section{Drivers and Barriers}

- What are some of the main drivers to introducing environmental management to a production?

- What are some of the main barriers to introducing environmental management to a production?

\section{Project-Based Enterprise}

- Are any of the barriers the result of the employee turnover from production to production? From only having a fixed time frame to develop and adopt a strategy on any one production?

- Is there an efficient way to move strategies from one production to another? 


\section{Appendix B: SWOT Analysis - Construction Industry}

The drivers and barriers identified in the literature were also classified into strengths, weaknesses, opportunities, and threats based on the SWOT analysis method. Just as in the film case, the construction PBO was used as the system boundary. Drivers and barriers that originate from within the PBO were classified as internal, and become strengths and weaknesses respectively. Drivers and barriers that originate from outside the PBO were classified as external, and are opportunities and threats respectively. Table 10 presents the SWOT analysis results for all identified drivers in the construction literature, and Table 11 for the identified barriers.

Thuvander et al. (2011) have already identified the drivers and barriers revealed in their research as internal or external; their analysis has not been changed, but simply classified via the SWOT analysis. 
Table 10

Construction industry driver SWOT analysis, based on a review of the literature

\begin{tabular}{|c|c|c|c|}
\hline Identified Driver & Source & $\begin{array}{l}\text { Internal } \\
/ \\
\text { External }\end{array}$ & SWOT \\
\hline Energy conservation & Manoliadis (2006) & Internal & Strength \\
\hline Resource conservation & Manoliadis (2006) & Internal & Strength \\
\hline $\begin{array}{l}\text { Land use regulations and } \\
\text { planning policies }\end{array}$ & Manoliadis (2006) & External & Opportunity \\
\hline Waste reduction measures & Manoliadis (2006) & Internal & Strength \\
\hline Energy technologies & Manoliadis (2006) & Internal & Strength \\
\hline Education and training & Manoliadis (2006) & Internal & Strength \\
\hline $\begin{array}{l}\text { Adoption of incentive } \\
\text { programs }\end{array}$ & Manoliadis (2006) & Internal & Strength \\
\hline $\begin{array}{l}\text { Re-engineering the design } \\
\text { process }\end{array}$ & Manoliadis (2006) & Internal & Strength \\
\hline $\begin{array}{l}\text { Indoor environmental } \\
\text { quality }\end{array}$ & Manoliadis (2006) & Internal & Strength \\
\hline $\begin{array}{l}\text { Performance based } \\
\text { standards }\end{array}$ & Manoliadis (2006) & Internal & Strength \\
\hline $\begin{array}{l}\text { Better ways to measure } \\
\text { and account for costs }\end{array}$ & Manoliadis (2006) & Internal & Strength \\
\hline $\begin{array}{l}\text { Product innovation and } \\
\text { certification }\end{array}$ & Manoliadis (2006) & External & Opportunity \\
\hline $\begin{array}{l}\text { New kinds of partnerships } \\
\text { and project stakeholders }\end{array}$ & Manoliadis (2006) & External & Opportunity \\
\hline $\begin{array}{l}\text { Proactive role of materials } \\
\text { manufacturing }\end{array}$ & Manoliadis (2006) & External & Opportunity \\
\hline $\begin{array}{l}\text { Recognition of commercial } \\
\text { buildings as productivity } \\
\text { assets }\end{array}$ & Manoliadis (2006) & External & Opportunity \\
\hline Environmental protection & Shen and Tam (2002) & Internal & Strength \\
\hline $\begin{array}{l}\text { Reduced environmental } \\
\text { risks }\end{array}$ & Shen and Tam (2002) & Internal & Strength \\
\hline Corporate image & Shen and Tam (2002) & External & Opportunity \\
\hline $\begin{array}{l}\text { Improved public } \\
\text { environmental standards }\end{array}$ & Shen and Tam (2002) & External & Opportunity \\
\hline $\begin{array}{l}\text { Reduction of environmental } \\
\text { complaints }\end{array}$ & Shen and Tam (2002) & External & Opportunity \\
\hline $\begin{array}{l}\text { Reduction of environment- } \\
\text { related sickness and } \\
\text { injuries }\end{array}$ & Shen and Tam (2002) & Internal & Strength \\
\hline $\begin{array}{l}\text { Increasing overall business } \\
\text { competitiveness }\end{array}$ & Shen and Tam (2002) & External & Opportunity \\
\hline
\end{tabular}




\begin{tabular}{llcc}
\hline $\begin{array}{l}\text { Improving staff work } \\
\text { environment and morale }\end{array}$ & Shen and Tam (2002) & Internal & Strength \\
\hline $\begin{array}{l}\text { Cost saving due to reduced } \\
\text { fines and convictions }\end{array}$ & Shen and Tam (2002) & Internal & Strength \\
\hline Company image & Thuvander et al. (2011) & External & Opportunity \\
\hline Pleased personnel & Thuvander et al. (2011) & Internal & Strength \\
\hline Pleased management & Thuvander et al. (2011) & Internal & Strength \\
\hline Long-term profit & Thuvander et al. (2011) & External & Opportunity \\
\hline $\begin{array}{l}\text { Pleased } \\
\text { owners/shareholders }\end{array}$ & Thuvander et al. (2011) & External & Opportunity \\
\hline Product image & Thuvander et al. (2011) & External & Opportunity \\
\hline Competitive advantage & Thuvander et al. (2011) & External & Opportunity \\
\hline Cost savings & Thuvander et al. (2011) & Internal & Strength \\
\hline Sales & Thuvander et al. (2011) & External & Opportunity \\
\hline Recruitment & Thuvander et al. (2011) & External & Opportunity \\
\hline Market advantages & Thuvander et al. (2011) & External & Opportunity \\
\hline Market shares & Thuvander et al. (2011) & External & Opportunity \\
\hline Productivity & Thuvander et al. (2011) & Internal & Strength \\
\hline Short-term profit & Thuvander et al. (2011) & Internal & Strength \\
\hline Improved insurance terms & Thuvander et al. (2011) & External & Opportunity \\
\hline Improved financing terms & Thuvander et al. (2011) & External & Opportunity \\
\hline
\end{tabular}


Table 11

Construction industry barrier SWOT analysis, based on a review of the literature

\begin{tabular}{|c|c|c|c|}
\hline Identified Barrier & Source & $\begin{array}{c}\text { Internal } \\
/ \\
\text { External }\end{array}$ & SWOT \\
\hline $\begin{array}{l}\text { No demand for green } \\
\text { products / services }\end{array}$ & Thuvander et al. (2011) & External & Threat \\
\hline $\begin{array}{l}\text { Lack of willingness to } \\
\text { cooperate from customer }\end{array}$ & Thuvander et al. (2011) & External & Threat \\
\hline $\begin{array}{l}\text { Lack of willingness to } \\
\text { cooperate from suppliers }\end{array}$ & Thuvander et al. (2011) & External & Threat \\
\hline No competitive advantages & Thuvander et al. (2011) & External & Threat \\
\hline $\begin{array}{l}\text { No technical solutions } \\
\text { available }\end{array}$ & Thuvander et al. (2011) & External & Threat \\
\hline No regulatory incentives & Thuvander et al. (2011) & External & Threat \\
\hline Lack of relevant information & Thuvander et al. (2011) & External & Threat \\
\hline Lack of clear regulations & Thuvander et al. (2011) & External & Threat \\
\hline Lack of reliable information & Thuvander et al. (2011) & External & Threat \\
\hline $\begin{array}{l}\text { Lack of willingness to } \\
\text { cooperate within sector }\end{array}$ & Thuvander et al. (2011) & External & Threat \\
\hline No regulations & Thuvander et al. (2011) & External & Threat \\
\hline Cultural heritage demands & Thuvander et al. (2011) & External & Threat \\
\hline Lack of educated personnel & Thuvander et al. (2011) & Internal & Weakness \\
\hline $\begin{array}{l}\text { Lack of knowledge on } \\
\text { available tools }\end{array}$ & Thuvander et al. (2011) & Internal & Weakness \\
\hline Too costly & Thuvander et al. (2011) & Internal & Weakness \\
\hline Lack of financial resources & Thuvander et al. (2011) & Internal & Weakness \\
\hline Communication difficulties & Thuvander et al. (2011) & Internal & Weakness \\
\hline $\begin{array}{l}\text { Insufficient organizational } \\
\text { structure }\end{array}$ & Thuvander et al. (2011) & Internal & Weakness \\
\hline $\begin{array}{l}\text { Lack of management } \\
\text { support }\end{array}$ & Thuvander et al. (2011) & Internal & Weakness \\
\hline $\begin{array}{l}\text { Counteracting } \\
\text { organizational structure }\end{array}$ & Thuvander et al. (2011) & Internal & Weakness \\
\hline Organizational difficulties & Thuvander et al. (2011) & Internal & Weakness \\
\hline $\begin{array}{l}\text { Increase in management } \\
\text { and operation costs }\end{array}$ & Shen and Tam (2002) & Internal & Weakness \\
\hline $\begin{array}{l}\text { Lack of trained staff and } \\
\text { expertise }\end{array}$ & Shen and Tam (2002) & Internal & Weakness \\
\hline Lack of client support & Shen and Tam (2002) & External & Threat \\
\hline $\begin{array}{l}\text { Time-consuming for } \\
\text { improving environmental } \\
\text { performance }\end{array}$ & Shen and Tam (2002) & Internal & Weakness \\
\hline
\end{tabular}




\begin{tabular}{llll}
\hline $\begin{array}{l}\text { Lack of supplier co- } \\
\text { operation }\end{array}$ & Shen and Tam (2002) & External & Threat \\
\hline $\begin{array}{l}\text { Difficult co-ordination of } \\
\text { environmental performance } \\
\text { among multi-tier } \\
\text { subcontractors }\end{array}$ & Shen and Tam (2002) & External & Threat \\
\hline $\begin{array}{l}\text { Lack of working staff } \\
\text { support }\end{array}$ & Shen and Tam (2002) & Internal & Weakness \\
\hline $\begin{array}{l}\text { Increase in documentation } \\
\text { workload }\end{array}$ & Shen and Tam (2002) & Internal & Weakness \\
\hline $\begin{array}{l}\text { Lack of technological } \\
\text { support within organization }\end{array}$ & Shen and Tam (2002) & Internal & Weakness \\
\hline $\begin{array}{l}\text { Lack of tailor-made training } \\
\text { on environmental } \\
\text { management }\end{array}$ & Shen and Tam (2002) & Internal & Weakness \\
\hline $\begin{array}{l}\text { Lack of government legal } \\
\text { enforcement }\end{array}$ & Shen and Tam (2002) & External & Threat \\
\hline $\begin{array}{l}\text { Change of existing practice } \\
\text { of company structure and } \\
\text { policy }\end{array}$ & Shen and Tam (2002) & Internal & Weakness \\
\hline $\begin{array}{l}\text { Sustainability measure not } \\
\text { considered by stakeholders }\end{array}$ & Williams and Dair (2007) & External & Threat \\
\hline $\begin{array}{l}\text { Sustainability measure was } \\
\text { not required by client / end } \\
\text { user }\end{array}$ & Williams and Dair (2007) & External & Threat \\
\hline $\begin{array}{l}\text { Stakeholder had no power } \\
\text { to enforce or require } \\
\text { sustainability measure }\end{array}$ & Williams and Dair (2007) & External & Threat \\
\hline $\begin{array}{l}\text { One sustainability measure } \\
\text { was foregone in order to } \\
\text { achieve another }\end{array}$ & Williams and Dair (2007) & External & Threat \\
\hline $\begin{array}{l}\text { Sustainability measure was } \\
\text { restricted by regulators }\end{array}$ & Williams and Dair (2007) & External & Threat \\
\hline $\begin{array}{l}\text { Sustainability measure cost } \\
\text { too much }\end{array}$ & Williams and Dair (2007) & Internal & Weakness \\
\hline $\begin{array}{l}\text { Site conditions mitigated } \\
\text { against the use of a } \\
\text { sustainability measure }\end{array}$ & Williams and Dair (2007) & Internal & Weakness \\
\hline $\begin{array}{l}\text { Inadequate, untested, or } \\
\text { unreliable sustainability } \\
\text { materials, products or } \\
\text { systems (including long } \\
\text { Sustainability measure was }\end{array}$ & Williams and Dair (2007) & External & Threat \\
\hline & & & \\
\hline
\end{tabular}




\begin{tabular}{llll}
\hline not available & & & \\
\hline $\begin{array}{l}\text { An unsuitable measure was } \\
\text { allowed by the regulator (no } \\
\text { driver for sustainable } \\
\text { alternative to be used) }\end{array}$ & Williams and Dair (2007) & External & Threat \\
\hline $\begin{array}{l}\text { Stakeholder was not } \\
\text { included in the } \\
\text { development process }\end{array}$ & Williams and Dair (2007) & External & Threat \\
\hline $\begin{array}{l}\text { Stakeholder lacked } \\
\text { information, awareness or } \\
\text { expertise to achieve } \\
\text { sustainability measure }\end{array}$ & Williams and Dair (2007) & External & Threat \\
\end{tabular}




\section{REFERENCES}

An incredibly green checklist on Hulk's TFS shoot. (2008, February 4). Playback: Canada's Broadcast and Production Journal, 77. Retrieved September 19, 2009, from ABI/INFORM Global. (Document ID: 1426570891).

Adams, M.A. \& Ghaly, A.E. (2007). Determining barriers to sustainability within the Costa Rican coffee industry. Sustainable Development, 15(4), 229-241.

Augenbroe, G.L.M., \& Pearce, A.R. (1998). Sustainable construction in the United States of America: A perspective to the year 2010. CIB-W82 Report.

Bakker, R. (2010). Taking stock of temporary organizational forms: A systematic review and research agenda. International Journal of Management Reviews,12, 466-486.

Bansal, P., \& Roth, K. (2000). Why companies go green: A model of ecological responsiveness. Academy of Management Journal, 717-736.

Barney, J. (1991). Firm resources and sustained competitive advantage. Journal of Management, 17(1), 99-120.

Barrett, P., \& Sexton, M. (2006). Innovation in small, project-based construction firms. British Journal of Management, 17, 331-346.

Bayer, S. and Gann, D. (2007). Innovation and the dynamics of capability accumulation in project-based firms. INNOVATION: management, policy \& practice, $10(3-4), 217-234$.

Bechky, B.A. (2006). Gaffers, gofers, and grips: Role-based coordination in temporary organizations. Organization Science, 17(1), 3-21.

Berg, B.L. (1989). Qualitative research methods for the social sciences. Toronto, ON: Allyn and Bacon.

Binning, C. (2009, January 26). No longer alien to reduce, reuse or recycle on set. Playback: Canada's Broadcast and Production Journal, 30. Retrieved September 19, 2009, from ABI/INFORM Global. (Document ID: 1636333871).

Bresnen, M., Goussevskaia, A. \& Swan J. (2005). Organizational routines, situated learning and processes of change in project-based organizations. Project Management Journal, 36(3), 27-41. 
British Columbia Film Commission. (2011). Reel Green Overview. British Columbia Film Commission. Retrieved on July 18, 2011 from http://www.bcfilmcommission.com/community/reel_green_bc.php.

British Standards Institution. (2011). BSI BS 8909 Guidance Notes.

Bowen, G. (2005). Preparing a qualitative research-based dissertation: Lessons learned. The Qualitative Report, 10(2), 208-222.

Carlson A.E. and Winer, A. (Eds.) (2006). Southern California Environmental Report Card 2006. Los Angeles, CA: UCLA Institute of the Environment.

Cox, A. and Thompson, I. (1997). 'Fit for purpose' contractual relations: Determining a theoretical framework for construction projects. European Journal of Purchasing and Supply Management, 3, 127-135.

Corbett, C.J., \& Turco, R. P. (2006). Sustainability in the motion picture industry. Report prepared for the Integrated Waste Management Board of the State of California by the University of California, Los Angeles, Institute of the Environment, November. Retrieved on July 1, 2010 from http://www. personal. anderson. ucla. edu/charles. corbett/papers/mpis_report.pdf.

Davenport, J. (2006). UK film companies: PBO lacking entrepreneurship and innovativeness? Creativity and Innovation Management, 15(3), 250-257.

DeFillippi, R.J., \& Arthur, M.B. (1998). Paradox in project-based enterprise: The case of film making. California Management Review, 40(2), 125-139.

DeFillippi, R.J., Arthur, M.B., \& Lindsay, V.J. (2008). On being a knowledge worker. Organizational Dynamics, 37(4), 365-377.

Denzin, N.K. \& Lincoln, Y.S. (Eds.) (2000). Handbook of qualitative research (2nd ed.). Thousand Oaks, CA: Sage Publications Inc.

DiMaggio, P.J., \& Powell, W.W. (1983). The iron cage revisited: Institutional isomorphism and collective rationality in organizational fields. American Sociological Review, 48(2), 147-160.

Eccles, R.G. (1981). The quasifirm in the construction industry. Journal of Economic Behavior and Organization, 2(1981), 335-357. 
Elsayed, K. \& Paton, D. (2009). The impact of financial performance on environmental policy: Does firm life cycle matter? Business Strategy and the Environment, 18, 397-413.

Engwall, M. (2003). No project is an island: linking projects to history and context. Research Policy, 32(5), 789-808.

Environmental Media Association. (n.d. a). Historical Timeline. Environmental Media Association. Retrieved on June 15, 2012 from http://www.ema-online.org/historical-timeline/.

Environmental Media Association. (n.d. b). Green Seal Recipients. Environmental Media Association. Retrieved on January 19, 2013 from http://www.ema-online.org/green-seal/

Environmental Media Association. (n.d. c). Green Seal Recipients. Environmental Media Association. Retrieved on June 19, 2012 from http://www.ema-online.org/ema-green-seal-recipients/

Environmental Media Association. (n.d. d). Green Seal Award Criteria (PDF file). Environmental Media Association.

Environmental Media Association. (n.d. e). EMA Green Seal Criteria Application (XLS file). Environmental Media Association.

Felder, M., Kulperger, L., Maleki, N. \& Weinberg, C. (2008a). Environmental assessment of the film-based industries. A report presented to Green Screen Toronto \& Project Partners. Toronto.

Felder, M., Kulperger, L., Maleki, N. \& Weinberg, C. (2008b). Green practices manual: Environmental options for the film-based industries. A report presented to Green Screen Toronto \& Project Partners. Toronto.

Felder, M., Kulperger, L., Maleki, N. \& Weinberg, C. (2009). Towards voluntary certification for the film-based industries. A report presented to Green Screen Toronto \& Project Partners. Toronto.

Ferriani, S., Corrado, R. \& Boschetti, C. (2005). Organizational learning under organizational impermanence: Collaborative ties in film project firms. Journal of Management and Governance, 9, 257-285.

Fessenden L. \& Ellenbogen, M. (1991). Low impact filmmaking. New York, NY: Terre Verde.

Fuerst, F. \& McAllister, P. (2009). An investigation of the effect of eco-labeling on office occupancy rates. Journal of Sustainable Real Estate, 1(1), 49-64. 
Fuerst, F. \& McAllister, P. (2011). Green noise or green value? Measuring the effects of environmental certification on office values. Real Estate Economics, 39(1), 45-69.

Fontana, A. \& Frey, J. (2000). The interview: From structured questions to negotiated test. In Denzin, N.K. \& Lincoln, Y.S. (Eds.), Handbook of qualitative research (2nd ed.) (pp. 645-668). Thousand Oaks, CA: Sage Publications Ltd.

Greenwald, S. \& Landry, P. (2009). This business of film: A practical guide to achieving success in the film industry. New York, NY: Lone Eagle.

Gluch, P., Gustafsson, M. \& Thuvander, L. (2009). An absorptive capacity model for green innovation and performance in the construction industry. Construction Management and Economics, 27, 451-464.

Gluch, P. \& Raisanen, C. (2009). Interactional perspective on environmental communication in construction projects. Building Research \& Information, 37(2), 164-175.

Goffman, E. (1961). Asylums. Garden City, NY: Anchor Books.

Goodman, R.A. \& Goodman, L.P. (1976). Some management issues in temporary systems: A study of professional development and manpower the theatre case. Administrative Science Quarterly, 21, 494-501.

Grabher, G. (2002). Cool projects, boring institutions: Temporary collaboration in social context. Regional Studies, 36(3), 205-214.

Grabher, G. (2004). Learning in projects, remembering in networks? Communality, sociality, and connectivity in project ecologies. European Urban and Regional Studies, 11(2), 103-123.

Greater London Authority. (2009). Green Screen. London, UK: Greater London Authority.

Guest, G. Bunce, A. \& Johnson, L. (2006). How many interviews are enough? An experiment with data saturation and variability. Field Methods, 18(1), 59-82.

Hartmann, A. (2006). The role of organizational culture in motivating innovative behaviour in construction firms. Construction Innovation: Information, Process, Management, 6(3), 159-172. 
Hobday, M. (2000). The project-based organization: An ideal form for managing complex products and systems? Research Policy, 29, 871893.

Hoffman, A. (2000). Competitive environmental strategy: A guide to the changing business landscape. Washington, DC: Island Press.

Horsthuis, C., Thomson, D.S. \& Fernie, S. (2012). The case for slack to promote innovative behaviour in construction organisations. In Proceedings of the 28th Annual ARCOM Conference, Edinburgh, 3 - 5 September 2012, 10pp.

Hughey, K.F.D., Tait, S.V. \& O'Connell, M.J. (2005). Qualitative evaluation of three 'environmental management systems' in the New Zealand wine industry. Journal of Cleaner Production, 13(12), 1175-1187.

International Council of Chemical Associations. (2013). Responsible Care. Retrieved on June 15, 2013 from http://www.iccachem.org/en/Home/Responsible-care/.

Kadefors A. (1995). Institutions in building projects: implications for flexibility and change. Scandinavian Journal of Management, 11(4), 395-408.

Kvale, S. (1996). InterViews: An introduction to qualitative research interviewing. Thousand Oaks, CA: Sage Publications.

"LEED rating system: its effect on SH\&E practices in construction" (2011). Professional Safety, 56(12), 25-27.

Luu, H.F. (2004). Voluntary environmental initiatives and environmental management: toward a cooperative approach for the future. Master's Degree Project. Faculty of Environmental Design, University of Calgary, Calgary, AB.

Manoliadis, O., Tsolas, I., \& Nakou, A. (2006). Sustainable construction and drivers of change in Greece: a Delphi study. Construction Management and Economics, 24, 113-120.

Marshall, C. \& Rossman, G.B. (1999). Designing qualitative research (3rd ed.). Thousand Oaks, CA: Sage Publications Ltd.

Marshall, S.R., Cordano, M. \& Silverman, M. (2005). Exploring individual and institutional drivers of proactive environmentalism in the US wine industry. Business Strategy and the Environment, 14(2), 92-109. 
Miles, M.B. (Ed.). (1964). Innovation in education. New York, NY:

Teachers College Press.

Miles, M.B. (1978). On networking. Unpublished. Washington, DC: Centre for Policy Research, National Institute of Education.

Miller, N., Spivey, J., \& Florance, A. (2008). Does green pay off? Journal of Real Estate Portfolio Management, 14(4), 385-400.

Miner, A.S. \& Mezias, S.J. (1996). Ugly duckling no more: Pasts and futures of organizational learning research. Organization Science, 7(1), 88-99.

Minocha, S. \& Stonehouse, G. (2006). The "learning trap": A Bollywood frame for strategic learning. Management Decision, 44(10), 1344-1362.

Motion Picture Association of America. (n.d.). Theatrical market statistics 2011. Industry Reports. Motion Picture Association of America. Retrieved on June 12, 2012 from http://www.mpaa.org/Resources /5bec4ac9-a95e-443b-987b-bff6fb5455a9.pdf.

Moul, Charles C. (2005). Concise handbook of movie industry economics. Cambridge, UK: Cambridge University Press.

Munhall, P.L. (2008). In Chenail, R.J. (Ed.), Qualitative research proposals and reports: A Guide (3rd ed.). Toronto, ON: Jones \& Bartlett Publishers.

New Zealand Ministry of the Environment. (2005). Greening the screen. An environmental toolkit for the New Zealand screen production industry. Wellington, NZ: Ministry of the Environment.

Newell, S. \& Edelman, L.F. (2008). Developing a dynamic project learning and cross-project learning capability: synthesizing two perspectives. Information Systems Journal, 18, 567-591.

Nohria, N. \& Gulati, R. (1997). What is the optimum amount of organizational slack? A study of the relationship between slack and innovation. European Management Journal, 15(6), 603-611.

Ontario Media Development Corporation. (n.d.). Mission statement. Ontario Media Development Corporation. Retrieved November 21, 2012 from http://www.omdc.on.ca/Page3286.aspx

Oxford Economics. (2010). The economic impact of the UK film industry. Retrieved on September 21, 2012 from http://www.ukfilmcouncil.org.uk 
/media/pdf/i/r/The_Economic_Impact_of_the_UK_Film_Industry__June_2010.pdf.

Padgett, D.K. (2008). Qualitative methods in social work research (Vol. 36). Thousand Oaks, CA: Sage Publications Ltd.

Patton, M.Q. (1990). Qualitative evaluation and research methods (2 ${ }^{\text {nd }}$ ed.). Newbury Park, CA: Sage Publications Ltd.

Paulraj, A. (2009). Environmental motivations: A classification scheme and its impact on environmental strategies and practices. Business Strategy and the Environment, 18, 453-468.

Perren, A. \& Schatz, T. (2004). "Hollywood". Communication Faculty Publications. Paper 2, Georgia State University. Retrieved on September 12, 2012 from http://digitalarchive.gsu.edu/communication_facpub/2.

Phelan, S. \& Lewin, P. (1999). Paradox in project-based enterprise: What aradox? (Letter to the Editor). California Management Review, 42(1), 180-186.

Prahalad, C.K. \& Hamel, G. (1990). The core competence of the corporation. Harvard Business Review, 33(May-June 1990), 79-91.

Producers Guild of America. (2010). Green Production Guide. Retrieved on January 10, 2012 from http://www.greenproductionguide.com.

Punch, K.F. (1998). Introduction To Social Research: Quantitative and Qualitative Approaches. Thousand Oaks, CA: Sage Publications Ltd.

Rivera, J. (2002). Assessing a voluntary environmental initiative in the developing world: The Costa Rican certification for sustainable tourism. Policy Sciences, 35(4), 333-360.

Salter, A. \& Gann, D. (2003). Sources of ideas for innovation in engineering design. Research Policy, 32(8), 1309-1324.

Scott, W. R. (2008). Approaching adulthood: The maturing of institutional theory. Theory and Society, 37(5), 427-442.

Seidman, I.E. (1991). Interviewing as Qualitative Research. New York, NY: Teachers College Press.

Sharma, S. (2000). Managerial interpretations and organizational context as predictors of corporate choice of environmental strategy. Academy of Management Journal, 43(4), 681-697. 
Shen, L.Y. \& Tam, V.W.Y. (2002). Implementation of environmental management in the Hong Kong construction industry. International Journal of Project Management, 20, 535-543.

Silverman, D. (2005). Doing Qualitative Research. Thousand Oaks, CA: Sage Publications Ltd.

Silverman, M., Marshall, R. \& Cordano, M. (2005). The greening of the California wine industry. Journal of Wine Research, 16(2), 151-169.

Stinchcombe, A.L. (1985). Project administration in the North Sea. In Stinchcombe, A. \& Heimer, C. (Eds), Organization theory and project management: Administering uncertainty in Norwegian offshore oil. Bergen, Norway: Norwegian University Press.

Stoughton, L. (2005). Environmental management systems implementation, driving forces and barriers. M.E.Des. dissertation. University of Calgary, Calgary, AB.

Takahashi, T. \& Nakamura, M. (2009). The impact of operational characteristics on firms' EMS decisions: Strategic adoption of ISO 14001 certifications. Corporate Social Responsibility and Environmental Management, 2009.

Thompson, A. (April 2007). Studios go green, scene by scene. Variety, 406(11), 6-7. Retrieved September 20, 2009, from Research Library. (Document ID: 1279705001).

Thompson, D. (Ed.) (2002). Tools for Environmental Management. Gabriola Island, BC: New Society Publishers, Limited.

Thuvander, L., Gluch, P., Gustafsson, M. \& Baumann, H. (2011). Twelve years of environmental work in the Swedish Construction Industry. In Proceedings from the International Sustainable Building Conference, SB11, Helsinki.

U.S. Bureau of Economic Analysis. (2012). Value added by industry (interactive table). U.S. Bureau of Economic Analysis. Retrieved November 17, 2012 from http://www.bea.gov/iTable/index_industry.cfm.

Vanegas, J. and Pearce, A. (2000). Drivers for change: An organizational perspective on sustainable construction. In ASCE Construction Congress VI, 406-415.

Van Bueren, E. M. \& Priemus, H. (2002). Institutional barriers to sustainable construction. Environment \& Planning B: Planning \& Design 29(1), 75-86. 
Verrier, R. (2009, April 14). On-location film and TV shoots in L.A. hit lowest levels on record. Los Angeles Times. Retrieved from http://articles .latimes.com/2009/apr/14/business/fi-ct-filmshoots14.

X-Rates. (n.d.). Monthly Average U.S. Dollar per 1 British Pound. Retrieved September 21, 2012 from http://www.xrates.com/average/?from $=$ GBP\&to=USD\&year $=2009$

Williams, K. \& Dair, C. (2007). What is stopping sustainable building in England? Barriers experienced by stakeholders in delivering sustainable developments. Sustainable Development, 15(3), 135-147.

Winch, G. (1987) The construction firm and the construction process: The allocation of resources to the construction project. In Lansley, P. \& Harlow, P. (Eds), Managing Construction Worldwide, Vol. 2, London, U: E.\& F. N. Spon. 